\title{
Synthesis of Glycosides by Glycosynthases
}

\author{
Marc R. Hayes ${ }^{1}$ and Jörg Pietruszka ${ }^{1,2, *}$ \\ 1 Institut für Bioorganische Chemie, Heinrich-Heine-Universität Düsseldorf im Forschungszentrum Jülich, \\ 52426 Jülich, Germany; m.hayes@fz-juelich.de \\ 2 Forschungszentrum Jülich, IBG-1: Biotechnology, 52426 Jülich, Germany \\ * Correspondence: j.pietruszka@fz-juelich.de; Tel.: +49-2461-61-4158
}

Received: 26 July 2017; Accepted: 28 August 2017; Published: 30 August 2017

\begin{abstract}
The many advances in glycoscience have more and more brought to light the crucial role of glycosides and glycoconjugates in biological processes. Their major influence on the functionality and stability of peptides, cell recognition, health and immunity and many other processes throughout biology has increased the demand for simple synthetic methods allowing the defined syntheses of target glycosides. Additional interest in glycoside synthesis has arisen with the prospect of producing sustainable materials from these abundant polymers. Enzymatic synthesis has proven itself to be a promising alternative to the laborious chemical synthesis of glycosides by avoiding the necessity of numerous protecting group strategies. Among the biocatalytic strategies, glycosynthases, genetically engineered glycosidases void of hydrolytic activity, have gained much interest in recent years, enabling not only the selective synthesis of small glycosides and glycoconjugates, but also the production of highly functionalized polysaccharides. This review provides a detailed overview over the glycosylation possibilities of the variety of glycosynthases produced until now, focusing on the transfer of the most common glucosyl-, galactosyl-, xylosyl-, mannosyl-, fucosyl-residues and of whole glycan blocks by the different glycosynthase enzyme variants.
\end{abstract}

Keywords: biocatalysis; glycoside; polysaccharide; glycosidase; glycosynthase; synthesis; glycosylation

\section{Introduction}

With the increasingly growing knowledge of the major role glycosides and glycoconjugates play in biological processes, the demand for simple methods for the synthesis of defined glycosides is constantly rising. Their high biological functionality and complex structure is a result of their numerous functional moieties, diverse stereochemistry, and numerous linkage possibilities. Glycosidic structures are ubiquitous throughout Nature, covering the surface of all cellular organisms and even the macromolecules inside these. Therefore, glycosides fulfill many different functions in biological systems providing on the one hand, function, structure and stability for cells and enzymes, but also acting as recognition motifs, as for example, in blood group antigens. Many bacterial and viral infections are mediated by glycoside recognition, clearly demonstrating the importance of glycosides for the pharmaceutical industry [1]. Additionally, specific oligosaccharides, such as human milk oligosaccharides have been described to have probiotic and antimicrobial effects making them highly desired targets for the food and nutrition industry [2]. Polysaccharides also play an important role in discovering new sustainable materials as they originate from renewable resources. Synthesis of glycoside structures would therefore greatly improve the possibility in producing new pharmaceuticals and materials, and allow targeted research on functional and structural properties of these compounds.

The chemical synthesis of glycosides is well developed, but remains a laborious task, as many protection and selective deprotection steps are required to solely address single functional groups in order to avoid side product formation [3-6]. Complete anomeric control of the newly formed bond is also a prerequisite to avoid lengthy separation methods. Throughout nature the synthesis of 
glycosidic structures is accomplished by the enzyme group of glycosyltransferases. These enzymes transfer activated sugar nucleotide donor molecules selectively onto an acceptor molecule. Their use in biocatalysis has been extensively researched, but is still limited for a large scale by the high cost of the nucleotide-phosphate donors and difficulty in expression and handling of these mostly membrane bound enzymes [7]. Alternative carbohydrate active enzymes are glycohydrolases or glycosidases, of which a high variety are readily available due to their occurrence in the metabolic pathways of all organisms [8]. This group of enzymes naturally degrade glycosidic structures and are defined into two groups depending on their catalytic mechanism (Scheme 1A,B) [9]. Retaining glycosidases follow a double displacement catalyzed by a nucleophilic and acid/base residue in the enzymes active site resulting in a retention of the anomeric configuration of the substrate in the yielded product. Inverting glycosidases in comparison follow a single displacement mechanism with two catalytic acid/base residues supporting the nucleophilic substitution at the anomeric center of the substrate. Glycosidases can be utilized in synthetic reactions by reverse hydrolysis or transglycosylation methods $[10,11]$. Nevertheless, the ability of the glycosidase in hydrolyzing the produced product leads to strongly diminished yields. To overcome the disadvantage of product hydrolysis Mackenzie et al. and also Malet et al. (working on exo- and endo-glycosidases, respectively) reported the production of genetically engineered glycosidases, namely glycosynthases, which were lacking a nucleophilic residue and therefore void of hydrolytic activity [12,13]. However, the intact structure of the enzyme allowed the formation of glycosidic bonds in high yields in the presence of activated glycosyl donors such as glycosyl fluorides (Scheme 1C).

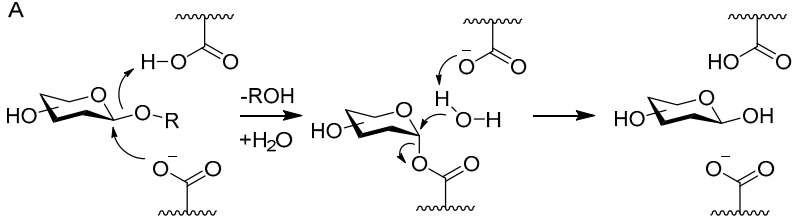

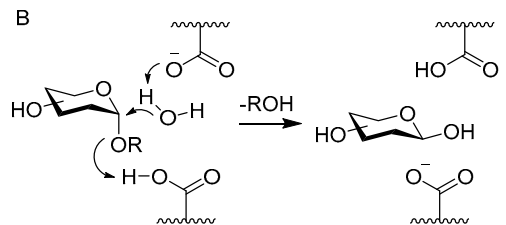

D
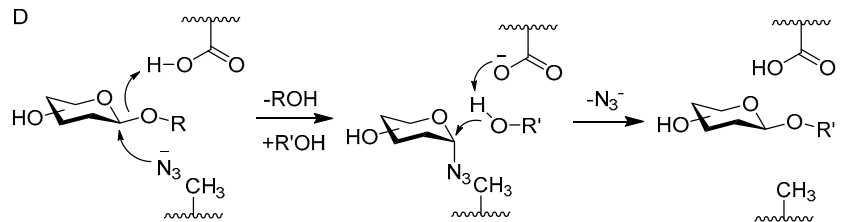

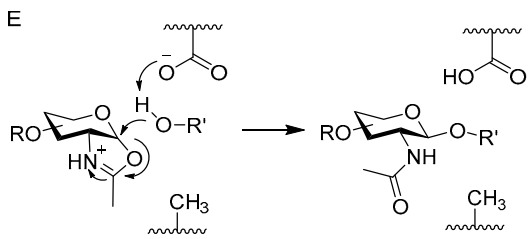

Scheme 1. Mechanisms of glycosyl hydrolases and synthases. (A) Retaining hydrolases follow a double displacement mechanism in which the enzyme forms a glycosyl-enzyme-intermediate by attacking the anomeric centre with a nucleophilic amino acid residue. The anomeric configuration of the substrate is retained in the product; (B) Inverting hydrolases follow a single displacement mechanism, which is supported by acid/base residues. The anomeric configuration of the product is inverted compared to the substrate; (C) 'Classic' glycosynthase mechanism involving an activated glycosyl donor in opposite configuration to the natural substrate. The product cannot be hydrolyzed due to the lack of a nucleophilic residue; (D) Alternative glycosynthase mechanism producing the activated donor in situ with an external nucleophile (azide, formate or acetate ion); (E) Glycosynthases derived from endo- $\beta$ - $N$-acetylglucosaminidases transfer oxazoline glycoside donors to variable acceptors.

Since the introduction of this 'classical' glycosynthase method mostly restricted to retaining glycosidases, alternative methods such as in situ generation of donor molecules have been reported, 
expanding the repertoire of glycosynthases greatly [14]. Glycosidases of various origins have been transformed into glycosynthases enabling the production of $\alpha$ - and $\beta$-glycosyl linkages with glucosyl, galactosyl-, fucosyl-, arabinosyl-, mannosyl- or even lactosyl-residues [15]. Most recently, the method has been transferred to endo- $\beta-N$-acetylglucosaminidases, such as Endo-M of $M$. hiemalis, which play important roles in protein post-translational glycosylation. Elucidation of the mechanistic properties of these enzymes led to the development of synthase-like mutants, which transfer oxazoline glycoside structures onto acceptors enabling the en bloc transfer of large glycans [16]. This has resulted in a powerful tool for modifying peptides with high pharmaceutical interest with defined glycan structures.

There are many excellent reviews on the topic of enzymatic glycoside synthesis, which give a great overview of the biocatalytic methods but manly focus on the production and mechanistic studies of glycosynthases [10,17-19]. This review will focus on the synthesis of glycosides employing glycosynthase methods, only, summarizing in each section the findings of a specific glycosyl residue also giving an overview of described products, which have been synthesized, rather than focusing on the production of the glycosynthase itself.

\section{Glycoside Syntheses Using Glycosynthase Methods}

\subsection{Glucosynthases}

Since the introduction of the genetically engineered glycosynthases by Mackenzie et al. in 1998, glucosynthases derived from glucosidases (exo or endo) originating from a variety of organisms have been the most commonly produced type of these enzymes [12]. This type of variant is also often named generally 'glycosynthase' throughout literature, due to the often-observed promiscuity in regard to the donor glycoside. The Abg E358A glycosynthase, for example, catalyzed not only the transfer of glucosyl but also galactosyl residues to para-nitrophenyl (pNP) glycosides. Further modulation of this enzyme broadened the scope of donor substrates as reported by Shim et al. and Kim et al. [20,21]. The use of the glycosynthase variant Abg NNT was thereby extended to C3-modified (methylated) gluco- and galactosyl donors (producing $\beta-1,4$ linkages) and Abg 2F6 to a xylosyl donor (Section 2.3), giving a much broader range of synthesizable glycosides. The promiscuity of glycosynthases to accept different glycosyl fluoride donors was also impressively demonstrated by Wei et al. with the $\beta$-glycosidase mutant TnG E338A of T. nonproteolyticus [22]. The glycosynthase showed high variability towards the donor molecule, transferring $\alpha$-D-glucosyl, $\alpha$-D-galactosyl, and $\alpha$-D-fucosyl fluoride donors $(\mathbf{1}, \mathbf{2}$ and 3$)$ to different acceptors $4-8$ in yields for $\mathbf{9 - 1 3}$ varying between $15-100 \%$ depending on the donor and acceptor combination (Table 1). Interestingly the enzyme also exhibited activity towards dihydroisoandrosterone (5), an unusually large, lipophilic acceptor, with $\alpha$-D-glucosyl fluoride $(\alpha \mathrm{GlcF}, 1)$ as the donor glycoside ( $49 \%$ yield). An even broader donor scope was exhibited by the glycosynthase BGlu1 E386G originating from the $\beta$-glucosidase of rice examined by Pengthaisong et al. [23]. The glycosynthase was shown to transfer glycoside residues of $\alpha$-D-glucosyl (1), $\alpha$-D-galactosyl (2), $\alpha$-D-fucosyl (3), $\alpha$-D-arabinosyl, $\alpha$-D-xylosyl (14), and $\alpha$-D-mannosyl (15) fluoride donor to pNP-cellobioside 8 producing yields of $57 \%$, $59 \%, 42 \%$, 99\%, $3 \%$ and $79 \%$, respectively.

The use of the Abg E358S glycosynthase in the synthesis of natural or unnatural glycosides was also demonstrated efficiently by Fairwether et al. in the synthesis of glycosylated versions of methyl $\beta$-acarviosin (16), an inhibitor of cellulases (Scheme 2a) [24]. The inhibitor was glucosylated $(\beta-1,4)$ to the tri- 17 and tetrasaccharide 18 in yields of $42 \%$ and $6 \%$, respectively.

Further putative cellulase inhibitors, variants of isofagomine and tetrahydrooxazine were produced by MacDonald et al. producing a mixture of cello-oligosaccharide inhibitor variants with different lengths [25]. The reported glucosylation of erythromycin A (19) by Jakeman et al. showed the possibility of transferal of a glucosyl residue $(\beta-1,2)$ to a more complex type of acceptor in a yield of $14 \%$ (20, Scheme 2b) [26]. 
Table 1. Examples of synthetic glycosylation products catalyzed by the TnG E338A [22]. Reactions were carried out with $\alpha$-D-GlcF (1), $\alpha$-D-GalF (2), or $\alpha$-D-FucF (3) as the donor. Donor and acceptor molecules were employed in equal amounts unless otherwise noted. Yields were determined after purification or isolation.

(n)

${ }^{\text {a }}$ Donor was used in 2 equivalents.

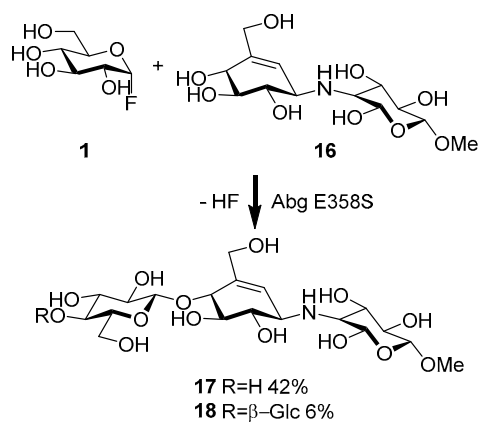

(a)

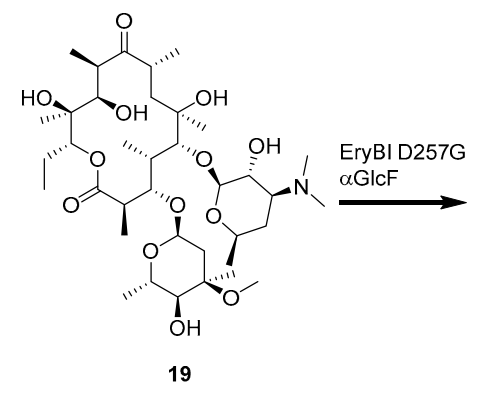

(b)

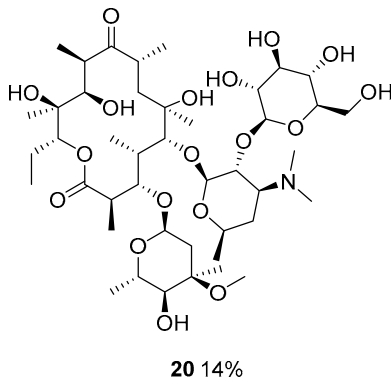

)

Scheme 2. Glucosylation of natural and unnatural glycosides. (a) Synthesis of glucosylated methyl $\beta$-acarviosin (16) by Fairweather et al. [24]. The mono- and diglycosylated products 17, 18 were isolated in yields $42 \%$ and 6\%; (b) Glucosylation of erythromycin A (19) by the glucosynthase EryBI D257G [26]. The enzyme showed high tolerance towards the bulky dimethylated amino group in the C3 position.

In addition to the 'classical' glycosynthase approach catalyzing the transfer of glycosyl fluoride donors, Pozzo et al. improved glycosylation yields by utilizing the chemical rescue method for in situ donor production with the $\beta$-glucosynthase (TnBg11A E349G; GH1) of T. neapolitana [27]. The group achieved a $3.7 \times$ higher yield during the synthesis of quercetin-3,4'-di-O- $\beta$-D-glucopyranoside with ortho-NPGlc and formate for in situ donor production, compared to the synthesis using 
$\alpha \operatorname{GlcF}(1,10 \%$ yield). This approach was subsequently transferred efficiently to the TnBgl3B D242A W243F (GH1; T. neapolitana) glycosynthase which exhibited transglucosylation activity to quercetin-3-O- $\beta$-D-glucopyranoside (30\%), quercetin-3-O- $\beta$-D-galactopyranoside $(40 \%)$, and quercetin (15\%) [28]. The chemical rescue method was also applied to the $\alpha$-glucosynthase variant of AglA from T. acidophilum (AglA D408G) enabling the synthesis of the putative tyrosinase inhibitor $\alpha-1,4$-D-glucosyl arbutin in 38\% yield [29]. Though most exo-glycosidase derived glycosynthases are limited to glycosyl transfer to glycosides, Yang et al. utilized the glycosynthase of HiCel7B, HiCel7B E197S in the glycosylation of non-glycosylated flavonoid structures (e.g., 21 and 22, Scheme 3) [30]. The former endo-cellulase catalyzed the transfer of lactosyl fluoride (23, LacF) with high selectivity to the $4^{\prime}-O$ position (position $\mathrm{Y}$ ) of four different flavonoids with yields ranging between $72-95 \%(\mathbf{2 4} / \mathbf{2 5}$, Scheme 3).

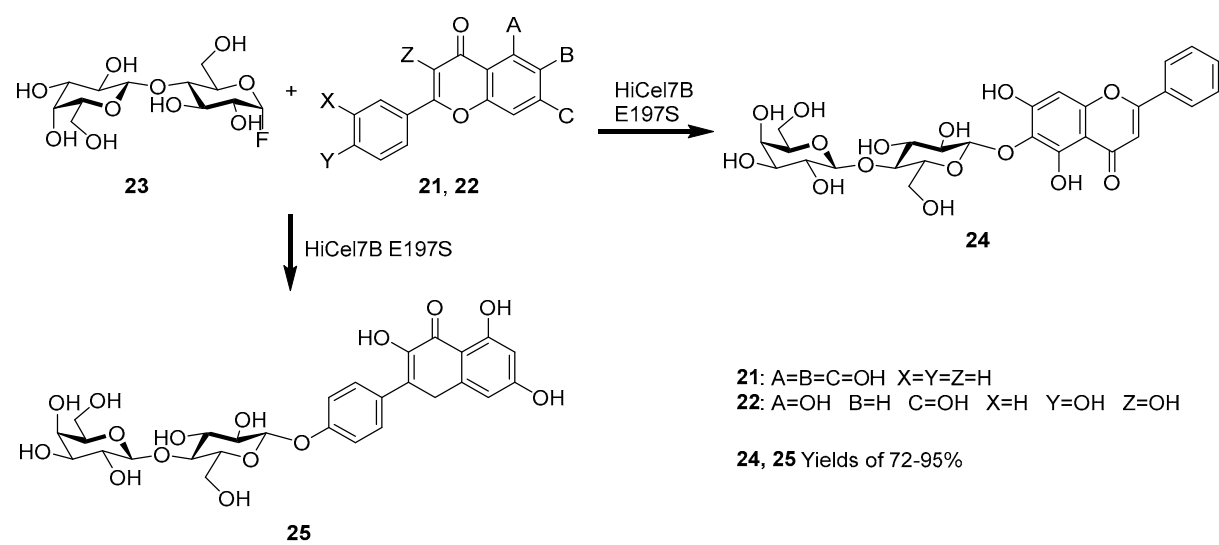

Scheme 3. Direct glycosylation of flavonoids 21 and 22 utilizing the glycosynthase HiCel7B E197S [30]. The enzyme exhibited high specificity for glycosylation of the hydroxyl function in the Y position (as for flavonoid 22) only deviating in the case of absence of this group as observed for the flavonoid 21. The yields of the flavonoid glycosylation ranged from $72-95 \%$.

A different variant of this enzyme, HiCel7B E197A was recently employed in the synthesis of regularly substituted, functionalized celluloses by Codera et al. [31]. Polymerization of $6^{\prime}$-azido- $\alpha$-cellobiosyl fluoride by HiCel7B E197A resulted in regularly azido substituted cellulose oligosaccharides with a degree of polymerization (DP) up to 32 in a yield of $88 \%$. A subsequent copper catalyzed azide/alkyne cycloaddition (Huisgen reaction) with alkyne functionalized Alexa Fluor die led to fluorescent polymers. The synthesis of a further polysaccharide was performed by Aragunde et al. [32]. The glycosynthase produced from the $\beta-1,3-1,4-$ glucanase of $B$. licheniformis catalyzed the oligomerization of the Glc- $\beta 1,4-G l c-\beta 1,3-G l c \alpha$ F donor reaching yields of $90 \%$ (weight polymer/weight initial donor).

\subsection{Galactosynthases}

Showing the importance of the glycosynthase method in the production of glycoside structures for biological or pharmaceutical research, Kwan et al. described the synthesis of the type 2 blood group A oligosaccharide 26 by combining the glycosynthase Abg 2F6 in a reaction sequence with glycosyltranfersases WbgL and BgtA (Scheme 4) [33]. The enzyme efficiently transferred $\alpha$-D-galactosyl fluoride $(2, \alpha \mathrm{GalF})$ onto methyl umbelliferone $\beta$ - $N$-acetylglucosamine (27, UM- $\beta$-GlcNAc) in yields of $84 \%$ (28). By exploitation of the chemical rescue method (Section 1, Scheme 1D) usually carried out in the case of $\alpha$-glycosynthases, Strazulli et al. catalyzed the formation of various $\beta$-galactosyl glycosides by the $\beta$-galactosynthase Aa $\beta$ Gal D361G (A. acidocaldarius) and simple donor pNPGal as starting material [34]. Though a high transglycosylation was achieved, the enzyme showed high promiscuity producing different regioisomers and polyglycosylated products. 


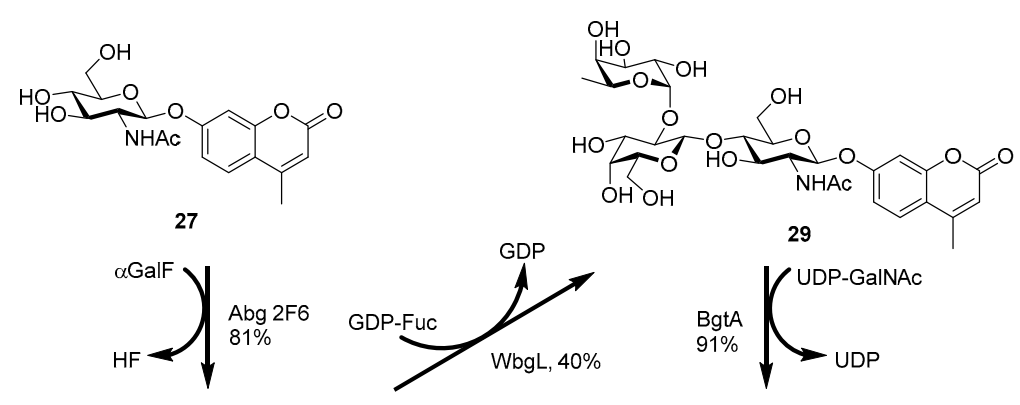

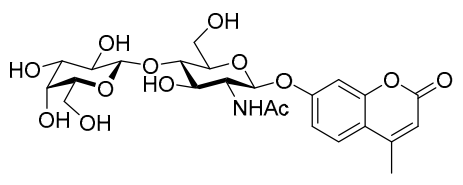

28

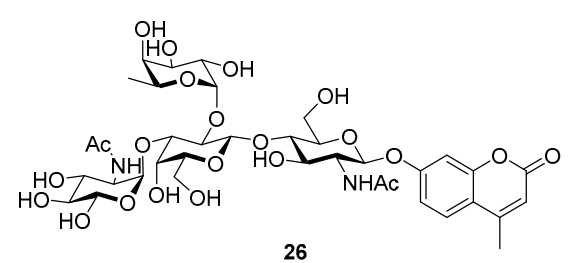

Scheme 4. Synthesis of the methyl umbelliferone derivative of the type 2 blood group A oligosaccharide 26 performed by Kwan et al. [33]. The synthesis combined the engineered glycosynthase Abg 2F6 (A19T, E358G, Q248R, M407V) with two glycosyltransferases WbgL and BgtA. The glycosyltranferases could also be employed in a one-pot reaction giving a higher yield of $62 \%$ compared to the total yield of $36 \%$ for the sequential reaction.

Goddard-Borger et al. demonstrated the use of a glycosynthase in the synthesis of psychosine, a $\beta$-D-galactopyranosyl sphingosine found in the central nervous system [35]. Accumulation of this compound can lead to neural signaling dysfunction often observed in individuals with Krabbe disease. The $\beta$-glycosynthase EGALC E341S (endo-galactosyl ceramidase of $R$. equi) was successfully employed in the one step synthesis of psychosine from $\alpha \mathrm{GalF}(2)$ and sphingosine (30) in a yield of $21 \%$, the yield being limited mainly by problems involving the low solubility of sphingosine (30) and precipitation of the enzyme. Further glycosphingolipids were synthesized by the effective combination of glycosyltransferases and endo-glycoceraminidase (EGCase) derived synthases. Rich et al. described the synthesis of the glycolipid lyso- $\mathrm{G}_{\mathrm{M} 3}$ (31) by combining lactosyl fluoride (23) with sphingosine (30) catalyzed by EGCase II D351S and subsequent sialylation with the Cst-I $\alpha-2,3$-sialyltransferase reaching an overall yield of $51 \%$ (31, Scheme 5) [36].

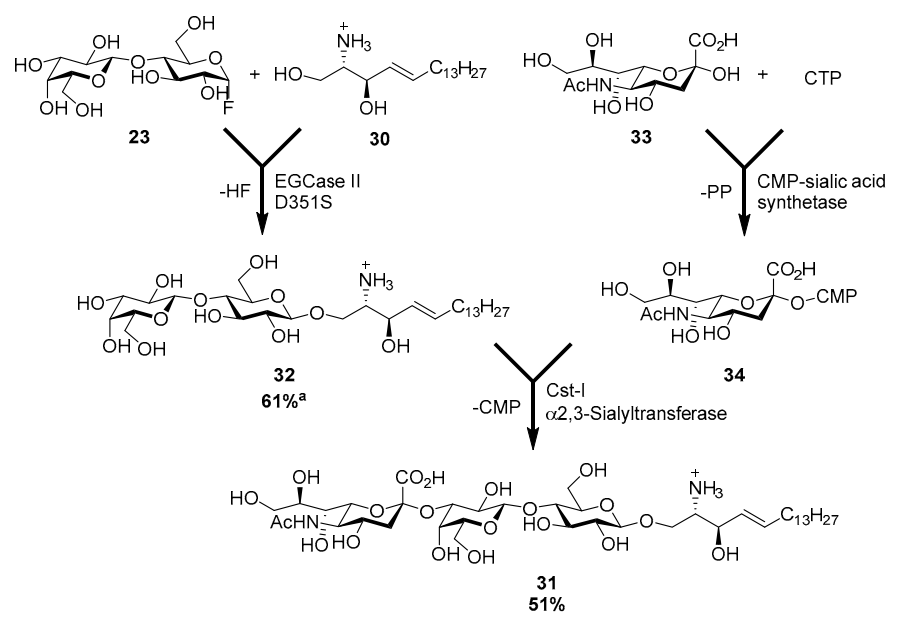

Scheme 5. Synthesis of the glycolipid lyso- $\mathrm{G}_{\mathrm{M} 3}$ (31) by Rich et al. [36]. The production of the lactosyl sphingosine acceptor 32 for the Cst-I $\alpha$-2,3-sialyltransferase was catalyzed by the EGCase II glycosynthase in an overall yield of $61 \%$. ${ }^{a}$ Yield encompassing the chemical synthesis of LacF (23) and the glycosynthase reaction. 
Yang et al. broadened the same synthesis to a FRET-probe of lyso- $\mathrm{G}_{\mathrm{M} 3}$ in order to visualize enzymatic processing of the glycolipid [37]. Another combination of glycosyltransferases and a glycosynthase was performed in sequential and also one-pot reactions by Henze et al. [38]. The report demonstrates the synthesis of $N$-acetyllactosamine type 1 (-3-Gal- $\beta 1,3-G l c N A c-1-)$ and type 2 (-3-Gal- $\beta 1,4-G l c N A c-1-)$ oligomers by combining the glycosynthase $\mathrm{His}_{6}{ }_{6} \mathrm{BgaC} \mathrm{D} 233 \mathrm{G}$ (B. circulans) either in a one-pot or sequentially with the glycosyltransferases $\beta 3$ GlcNAcT (H. pylori) and the $\beta$ GalT-1 (human origin) [39]. By sequential use of these enzymes, it was even possible to create neo- $N$-acetyllactosylamine (LacNAc) oligomers with alternating type 1 and type 2 units.

Even though much research and many advances have occurred in the synthesis of $\beta$-Gal linkages, the synthesis of $\alpha$-Gal linkages utilizing $\alpha$-galactosynthases is still limited. Cobucci-Ponzano et al. reported the effective conversion of $\beta$-D-galactopyranosyl azide $\left(35, \beta \mathrm{GalN}_{3}\right)$ to $\alpha$-galactooligosaccharides by the glycosynthase TmGalA D327G derived from T. maritima [40]. The enzyme produced galacto-oligosaccharides in good yields and the method was recently expanded by Okuyama et al. to the in situ formation of a $\beta$-D-galactosyl formate donor (36), which exhibited a higher transglycosylation rate compared to the azide donor (35, Scheme 6) [41]. The method allowed the galactosylation of carbohydrates such as glucose $(\alpha-1,1-\beta)$, xylose $(\alpha-1,4)$, maltose $(\alpha-1,1-\beta)$, cellobiose $(\alpha-1,1-\beta ; \alpha-1,6)$, lactose $(\alpha-1,1-\beta)$, and pNP derivatives of glucose (pNPGlc, 37), and mannose (pNPMan, 6; exclusively $\alpha-1,6$ ) in yields ranging from 75 to $95 \%$. Bayón et al. examined the addition of green co-solvents towards the synthesis of $\alpha$-galactosyl residues with $\beta G a l N_{3}(35)$ and reported increased conversion and yield for the glycosynthase TmGalA D327G producing $\alpha-1,6$ bonds with pNPGlc (37) and pNPMan (6) [42].

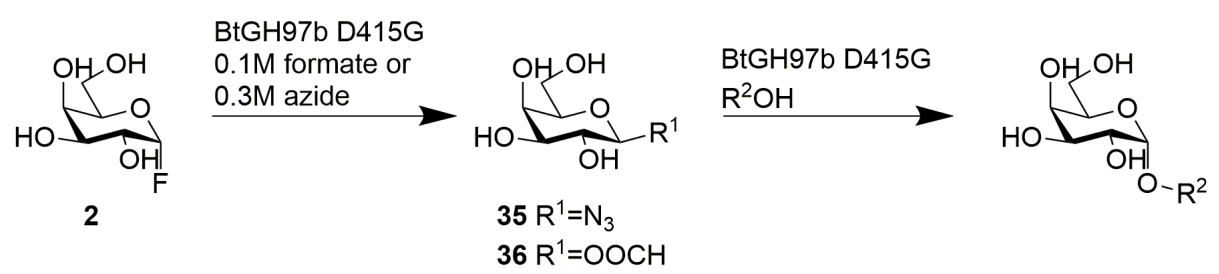

Scheme 6. In situ formation of the glycosyl donors $\beta \mathrm{GalN}_{3}$ (35) or $\beta \mathrm{Gal}$ formate (36) by incubation of $\alpha$ GalF (2) with glycosynthase BtGH97b D415G the additional external nucleophiles sodium azide of formate [41]. The in situ produced donor can then be subsequently transferred to a suitable acceptor $\left(\mathrm{R}^{2} \mathrm{OH}\right)$.

\subsection{Xylosynthases}

Xylooligosaccharides have gained much interest in the pharmaceutical industry, due to their anti-freezing activity, non-digestibility, non-cariogenic and beneficial properties for the intestinal flora [43]. One of the first approaches to the synthesis of xylosides was carried out by Kim et al. using the $\beta$-glycosynthase Abg 2F6 (A19T, E358G, Q248R, M407V) derived from a glucosidase from A. tumefaciens [21]. The glycosynthase variant exhibited a broad donor substrate range and showed an increased specificity to $\alpha$-D-xylosyl fluoride ( $\alpha$ XylF, $14 ; 34 \times$ higher) compared to the original mutant Abg E358G. This was then utilized in 2005 by the same group in the synthesis of xylosaccharides with pNPGlc $(37, \beta-1,4)$, pNPXyl $(38, \beta-1,3 / 1,4)$ and pNPXylobioside $\left(39, X_{1} l_{2}\right.$ pNP; $\left.\beta-1,4\right)$ as acceptors in yields of $35-98 \%$. Xylosylated 1-deoxyxylanojirimycin (40), a xylose derived nitrogen-containing inhibitor, was also synthesized by this mutant in a yield of $28 \%$ (acetylated product; Scheme 7) [44]. 


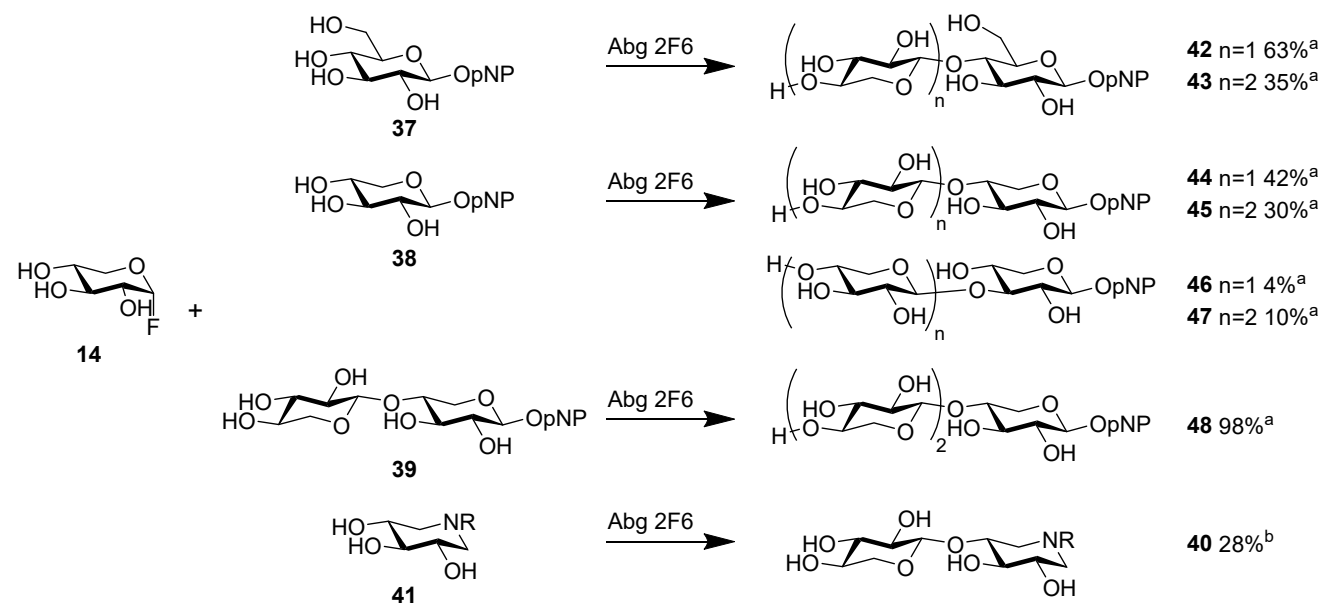

Scheme 7. Synthesis of various xylosides $\mathbf{4 0 , 4 2 - 4 8}$ by the glycosynthase Abg 2F6 derived from the $\beta$-glucosidase Abg of $A$. tumefaciens [44]. The enzyme exhibited variable selectivity depending on the acceptor substrate, producing predominantly $\beta-1,4$ linkages. ${ }^{\text {a }}$ Yields determined by HPLC analysis of the reaction mixture; ${ }^{b}$ Yield of isolated, acetylated product.

After these first syntheses, various groups accomplished the synthesis of xylooligomers with glycosynthases derived from actual xylanases. The reducing-end xylose-releasing exo-xylanase (REX) mutated in the acid/base catalytic residue (E236C) was utilized by Honda et al. in the synthesis of xylotrimers from xylobiosyl fluoride $\left(\mathrm{X}_{2} \mathrm{~F}, 49\right)$ and xylose [45]. This mutant enzyme was also the first report of a glycosynthase derived from an inverting glycosidase. Kim et al. also synthesized xylooligosaccharides with the CFXcd-E235G mutant of the retaining xylanase of $C$. fimi [46]. The enzyme catalyzed the oligomerization of $X_{2} \mathrm{~F}$ (49) and $X_{y} l_{2} \mathrm{pNP}$ (39) or benzylthio- $\beta$-xylobioside (Xy12BT) resulting in a mixture of oligomers ranging from xylotetrasaccharides to -dodecasaccharides with a total yield of transfer products of $61 \%$ and $66 \%$, respectively. The Sugimura et al. group expanded the repertoire of xylanase originating glycosynthses by four examples of the GH10 family (XylB T maritima; XynA B. halodurans; XynB C. stercorarium; Cex C. fimi) enabling the synthesis of xylooligomers from $\mathrm{X}_{2} \mathrm{~F}(50)$ in yields from $29-69 \%(7.8-18.4 \mathrm{mg})$ [47]. The products precipitated enabling easy isolation and were of high interest as unsubstituted xylan, a homopolymer of $\beta-1,4$-xylopyranose units, does not exist in nature. The production of larger xylooligomers was achieved by the group of Ben-David et al. [48]. The XynB2 E335G mutant of the retaining exo-glycosidase (GH52) of G. stearothermophilus catalyzed the synthesis of xylosides with $\alpha$ XylF (14) and pNPGlc (37), pNPXyl (38), and pNPMan (6) with a $\beta-1,4$ linkage in yields of $49 \%, 42 \%$ and $10 \%$ (disaccharide yields), respectively. By exploitation of the self-condensation of $\alpha \mathrm{XylF}$ (14) by the enzyme to $\mathrm{Xyl}_{2} \mathrm{~F}(49)$, a combinatorial synthesis with a glycosynthase of the xylanase XT6 (E265G; also of G. stearothermophilus) resulted in xylooligomer comprising of 6-100 monomers (Scheme 8) [48,49].
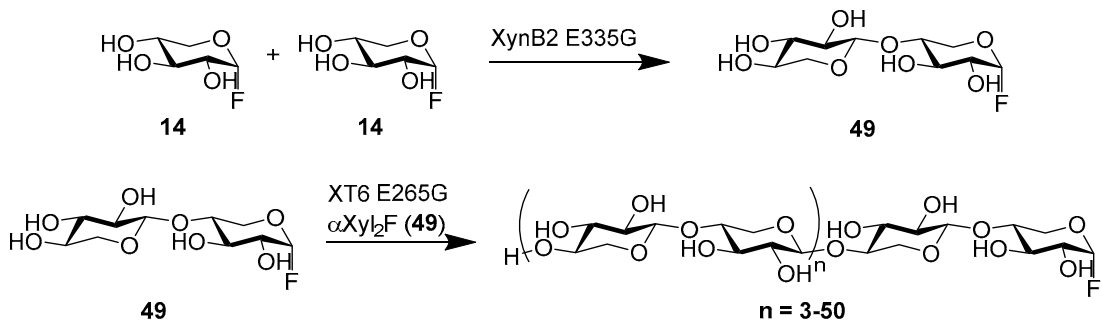

Scheme 8. Production of xylooligomers comprising 6-100 monomers by exploitation of the self-condensation of $\alpha \mathrm{XylF}(\mathbf{1 4})$ and $\mathrm{Xyl}_{2} \mathrm{~F}$ (49) catalyzed by the enzyme combination of XynB2 E335G and XT6 E265G [48,49]. 
The activity of the XynB2 E335G mutant in production of $\mathrm{Xyl}_{2} \mathrm{~F}(49)$ and $\mathrm{Xyl}_{3} \mathrm{~F}$ was improved by the development of a general screening assay utilizing the $\mathrm{pH}$ indicator Methyl Red, resulting in mutants with much higher $\mathrm{k}_{\mathrm{cat}}$ values than the original synthase [50]. However, the yields of the reactions catalyzed by the improved mutants were not reported. More recently Goddard-Borger et al. described the effective synthesis of various xylanase inhibitors by the exo- $\beta$-xylosidase mutant Bhx E334G (B. halodurans) [51]. The enzyme accepted different sugar derivatives such as thioglycosides, iminosugar derived carbamates, and a 2-deoxy-2-fluoroxyloside giving yields of $67-86 \%$ of glycosylated products (acetylated products). A further important type of xyloside are xyloglucans (an $\alpha-1,4$ glucan backbone containing $\alpha-1,6$-D-xylose branches) which are the principal hemicellulose component of the primary cell wall of plant cells and are also an abundant type of storage polysaccharide in seeds [52]. They often find use in the food, paper, textile, and pharmaceutical industry as for example cellulose crosslinkers or rheology modifiers (in fluid mechanics). The synthesis of xyloglucans, as custom polysaccharides, was recently carried out by Spaduit et al. with the broad-specificity xyloglucan glycosynthase PpXG5 E323G (P. pabuli) [53]. The group synthesized XXXG- (50) and XLLG-structure (51) type xyloglucans of molecular masses up to 30,000 $(n=29)$ and $60,000(n=44)$ by self-condensation of XXXG $\alpha \mathrm{F}$ (50) and XLLG $\alpha \mathrm{F}$ (51) donor blocks respectively (Scheme 9). These were subsequently modified to fucosylated XLFG type glucans with a ratio of 3:1 XLFG:XLLG catalyzed by the fucosyltransferase AtFUT1(originating from A. thaliana).

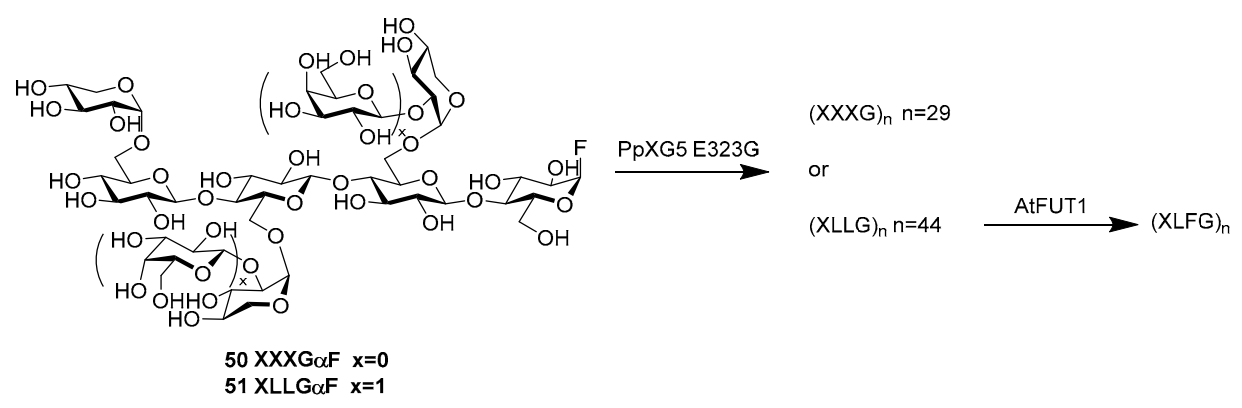

Scheme 9. Combinatorial glycosynthase/glycosyltransferase approach for the production of defined, homogenous xyloglucans [53]. Polysaccharide synthesis using compound $\mathbf{5 0}$ or $\mathbf{5 1}$ was catalyzed by PpXG5 E323G resulting in polymers with a maximal molecular weight of 30,000 $(n=29)$ and $60,000(n=44)$, respectively. Subsequent fucosylation by AtFUT1 reached a fucosylation of $75 \%$ of the oligosaccharide repeats. Nomenclature: $X=$ Xyl- $\alpha 1,6-G l c ; L=$ Gal- $\beta 1,2-X y l-\alpha 1,6-G l c ; F=$ Fuc- $\alpha 1,2-$ Gal- $\beta 1,2-X y 1-\alpha 1,6-G l c$.

\subsection{Mannosynthases}

Next to the xyloglucans, mannans are also highly abundant polysaccharides in plant cell walls and mannosyl moieties are common components of many biological structures such as $N$-linked glycans, microbial and viral antigens $[54,55]$. The enzymatic synthesis of $\beta$-mannosyl linkages has gained much interest as the chemical synthesis is complex and demanding as there are no beneficial effects promoting the synthesis of this anomeric configuration. The use of $\beta$-mannosynthases is therefore a simple and practical solution for the synthesis of this type of bond. Nevertheless, only little research has been carried out toward the creation of mannosynthases. Nashiru et al. created a $\beta$-mannosynthase by the glycosynthase method with a retaining $\beta$-mannosidase mutant of Man2a (E519S, GH2) of C. fimi [54]. The enzyme catalyzed the formation of $\beta-1,4$ (predominant linkage) and $\beta-1,3$ mannosides with $\alpha$-mannosyl fluoride (15, $\alpha$ ManF) and various acceptors (pNPMan (6), -Xyl (38), -Glc (37), -cellobioside (8), -gentiobioside, and 2,4-dinitrophenyl-2-deoxy-2-fluoro- $\beta$-mannoside) in yields from $70-99 \%$ comprising di-, tri-, and tetrasaccharides. The yield was mostly hampered due to the instability of $\alpha \operatorname{ManF}(\mathbf{1 5})$, which can easily undergo hydrolysis by epoxide-formation. The enzyme also exhibited high activity in chemical rescue experiments using 2,4-dinitrophenyl- $\beta$-D-mannosylpyranoside (52) 
and external nucleophiles such as azide, formate or acetate, but also with fluoride ions allowing an in situ production of the $\alpha \mathrm{ManF}$ donor (15, Scheme 10).

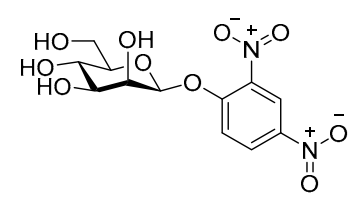

52

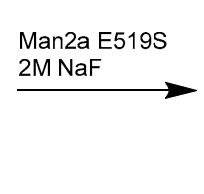

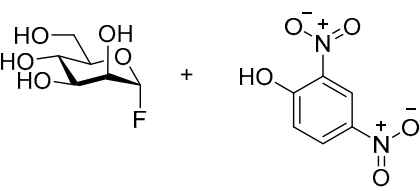

53

Scheme 10. In situ production of the glycosylation donor $\alpha \mathrm{ManF}(15)$ by exploiting the chemical rescue of hydrolytic activity of Man2a E519S in the presence of sodium fluoride as an external nucleophile [54].

Larger mannooligosaccharides were produced by Jahn et al. by biocatalysis using the glycosynthase derived from the $\beta$-mannosidase of $C$. japonicus Man26A [56]. The glycosynthase produced mannooligosaccharides using $\alpha \mathrm{Man}_{2} \mathrm{~F}$ as a donor and pNPGlc (37) as the acceptor in a total yield of $59 \%$. The tri- $(36 \%)$, penta- $(18 \%)$, and heptasaccharides $(5 \%)$ contained exclusively $\beta-1,4$ linkages. The acceptor pNPMan (6) on the other hand resulted in a trisaccharide in a 35\% yield. In contrast to these syntheses in which oligomerization of the product is observed, Yamamoto et al. described the possibility of mono-glycosylating acceptors with a glycosynthase derived from a broad glycosidase scaffold [55]. The $\alpha$-mannosynthase was created by mutation of an $\alpha$-glucosidase of $S$. solfataricus with a preferred hydrolysis of glucosides over mannosides. The synthase variant MalA D320G catalyzed the formation of oligosaccharides if $\beta \mathrm{GlcF}$ was used, but only mono-glycosylation in the case of the $\beta \mathrm{ManF}$ donor. The enzyme was tested on a variety of pNP-glycosides resulting in yields up to $77 \%(\alpha-1,4$ being the predominant type of linkage, $\alpha-1,3$ and 1,2 were also observed) and the preparation of naturally occurring $\alpha$-mannosyl motifs, such as Man- $\alpha(1,4)$-Glc, Man- $\alpha(1,3)$-L-Rha (54), and Man- $\alpha(1,2)-M a n$ $(55$, Table 2).

Table 2. Synthetic products of $\alpha$-mannosylation catalyzed by the MalA D320G [55]. All reactions were carried out with $\beta \mathrm{ManF}$ as the donor. Different regioselectivities were observed depending on the acceptor structure and anomeric configuration. Yields were determined after purification or isolation.

Ycceptor


The method also allowed the production of mannosylated myo-inositol (56/57) which is a component of the cell wall glycolipids of Mycobacterium tuberculosis. The mono-mannosylated inositols were isolated in a yield of $41 \%$ (mixture of Man- $\alpha(1,5)$ - and Man- $\alpha(1,1)$-myo-inositol 56 and 57 in a 3:1 ratio).

\subsection{Fucosynthases}

A further important group of compounds relevant in many biological processes are fucosyl residues. This deoxy-aldohexose exists in nature, in comparison to most natural carbohydrates, as a L-configured glycoside and linked predominantly in $\alpha$-configuration at the anomeric center. Many biological processes involve fucosylated compounds such as, cell-to-cell communication, cell development, recognition structures for pathogens, and antigenic structures.

The first synthesis of fucosylated structures using the glycosynthase method was reported by Wada et al. with a mutated $\alpha$-fucosidase of B. bifidum BbAfcA D766G [57]. The enzyme was successfully utilized in the synthesis of a Fuc- $\alpha(1,2)$-Gal linkage in $2^{\prime}$-fucosyllactose by combining $\beta$-fucosyl fluoride $(\beta \mathrm{FucF})$ with lactose. However, the low stability of $\beta$ FucF led to yields of $6 \%$. The yields caused by the instability of the $\beta$-fluoride donor were overcome by Cobucci-Ponzano et al. by the implementation of more stable $\beta$-azide fucosylpyranoside $\left(\beta \mathrm{FucN}_{3}\right)$ as donors for two new $\alpha$-fucosynthases [58]. The $\alpha$-fucosynthase SsD242S exhibited a wide acceptor range (shown for various aryl-glycosides) though also catalyzing the self-condensation of $\beta \mathrm{FucN}_{3}$ in all cases. In comparison, the second fucosynthase TmD224G demonstrated a more restricted acceptor range, but the self-condensation reaction was not observed. The reactions were also carried out with SsD242S in a preparative scale with total transfucosylation efficiencies ranging from 29-86\% (for the acceptors pNPXyl (38), pNPGal, and pNPGlcNAc (7)) providing mostly $\alpha-1,4$ and 1,3 linkages and additionally $\alpha-1,6$ linkages in the case of the galactoside acceptor. The mutant TmD224G could even reach a transfucosylation efficiency of $91 \%$ producing a mixture of Fuc- $\alpha(1,3)$ - and Fuc- $\alpha(1,4)-\beta-X y l p N P$ in a near 1:1 ratio. The application of $\alpha$-L-fucosynthases was more recently transferred to relevant biological structures such as epitopes of the antigens Lewis and ABO. Sakurama et al. reported the synthesis of the lewis antigens Le ${ }^{\mathrm{a}}$ and Le $^{\mathrm{x}}$ (Gal- $\beta 1,3 / 4$-(Fuc- $\left.\alpha 1,4 / 3\right)-G l c N A c: \mathrm{Le}^{\mathrm{a} / \mathrm{x}}$ 64/65) catalyzed by the 1,3-1,4- $\alpha$-L-fucosynthase BbAfcB D703S [59]. The antigen structures were created by the reaction of $\beta F u c F$ and lacto-N-biose I (66, LNB, Gal- $\beta(1,3)$-GlcNAc) and $N$-acetyllactosamine $(67$, LacNAc, Gal- $\beta(1,4)$-GlcNAc) resulting in yields of $47 \%$ and $55 \%$ for $\mathrm{Le}^{\mathrm{a}}(\mathbf{6 4})$ and $\mathrm{Le}^{\mathrm{x}}(65)$, respectively (Scheme 11$)$.

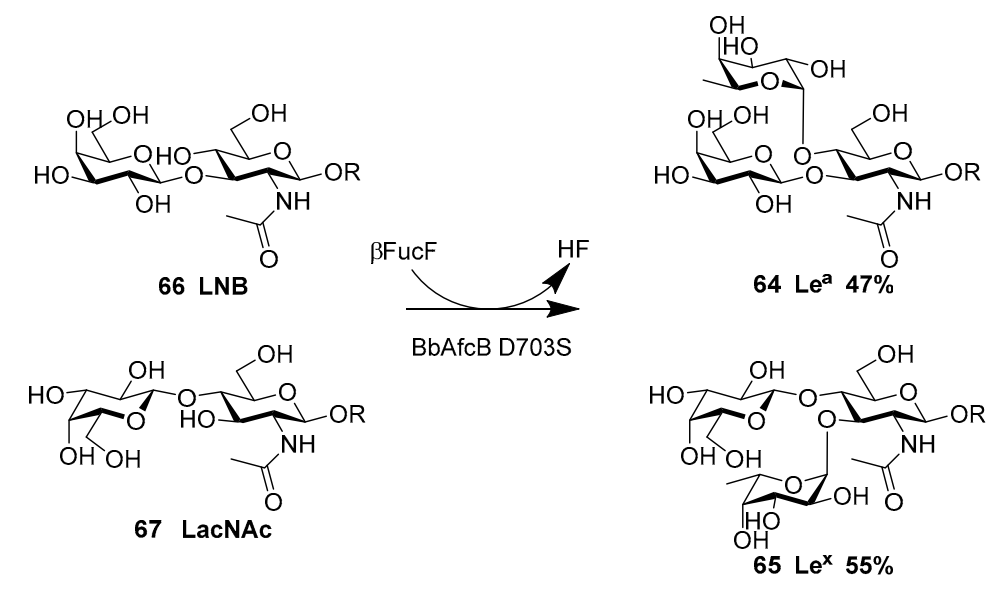

Scheme 11. $\alpha$-Fucosylation of LNB 66 or LacNAc 67 for the production of the Lewis antigens Le ${ }^{\text {a }}$ (64) and $\mathrm{Le}^{\mathrm{x}}(\mathbf{6 5})$, respectively, catalyzed by the $\alpha-1,3-1,4-\mathrm{L}-$ fucosynthase BbAfcB D703S [59].

An increase in yield using the more stable donor $\beta_{\mathrm{FucN}} \mathrm{N}_{3}$ as demonstrated by Cobucci-Ponzano et al. could not be achieved as no transfucosylation products could be observed with this donor. The enzyme also interestingly only acted on di- or trisaccharide acceptors unable to fucosylate monosaccharides 
such as, Glc, Gal, GlcNAc, and GalNAc. The specific production of lacto-N-fucopentaose II (LNFP II: Gal- $\beta 1,3-($ Fuc- $\alpha 1,4)$-GlcNAc- $\beta 1,3-$-Gal- $\beta 1,4-G l c)$ was also achieved in a yield of $41 \%$ with lacto- $N$-tetraose (LNT: Gal- $\beta 1,3-G l c N A c-\beta 1,3-G a l-\beta 1,4-G l c)$ as the acceptor.

The repertoire of synthesized antigen epitope structures was expanded by the work of Sugiyama et al. who introduced the 1,2- $\alpha$-L-fucosynthase BbAfcA N423H [60]. In addition to fucosylating many types of mono- and disaccharides, producing for example $\mathrm{H}$ type- 1 or $\mathrm{H}$ type-2 chains from LNB (66) or LacNAc (67) respectively, the antigens $\mathrm{Le}^{\mathrm{b}}$ and Le ${ }^{\mathrm{y}}$ (Fuc- $\alpha 1,2-$ Gal- $\beta 1,3 / 4$-(Fuc- $\alpha 1,4 / 3$ )-GlcNAc: $\mathrm{Le}^{\mathrm{b} / \mathrm{y}}$ ) were produced in yields of $43 \%$ and $62 \%$ from the $\mathrm{Le}^{\mathrm{a}}$ and $\mathrm{Le}^{\mathrm{x}}$ trisaccharides (64 and 65). In comparison to the BbAfcB D703S fucosynthase, BbAfcA N423H produced LNFP I (Fuc- $\alpha 1,2-$-Gal- $\beta 1,3-G l c N A c-\beta 1,3-G a l-\beta 1,4-G l c)$ rather than LFNP II with an efficiency of $75 \%$. Subsequently, the transfer of fucosyl residues to the non-reducing end of $O$-linked glycans was demonstrated by the successful reintroduction of $\mathrm{H}$-antigen structures to pretreated glycopeptide porcine gastric mucin. The application was even further extended by the group introducing $\mathrm{H}$-antigens to the non-reducing ends of $\mathrm{N}$ - and $\mathrm{O}$-glycans in fetuin glycoproteins, GM1 ganglioside (68), and a xyloglucan nonasaccharide [61]. It was demonstrated that BbAfcA N423H could fucosylate asialo-bi-, asialo-tri-, and monosialo-tri-antennary $\mathrm{N}$-glycan of the asialo fetuin glycopeptide with transfer efficiencies of $9 \%, 26 \%$, and $20 \%$ respectively. It was also possible to fucosylate the sialo form of the fetuin peptide containing di-sialo-bi-, di-sialo-tri, tri-sialo-tri, and tetra-sialo-tri-antennary glycans, yet with lower transfer efficiencies. The fucosylation of the xyloglucan nonasaccharide XLLG (51, Structure shown in Scheme 9) occurred with an efficiency of $57 \%$ resulting in a mixture of mono- $(\alpha-1,2-\mathrm{Gal})$, di$(\alpha-1,2-G a l)$, and trifucosylated ( $\alpha-1,3-G l c)$ XLLG glycosides. The enzyme also fucosylated glycolipids, transferring $\alpha-1,2$-fucosyl residue to the glycoside of the GM1 ganglioside (68, Scheme 12).

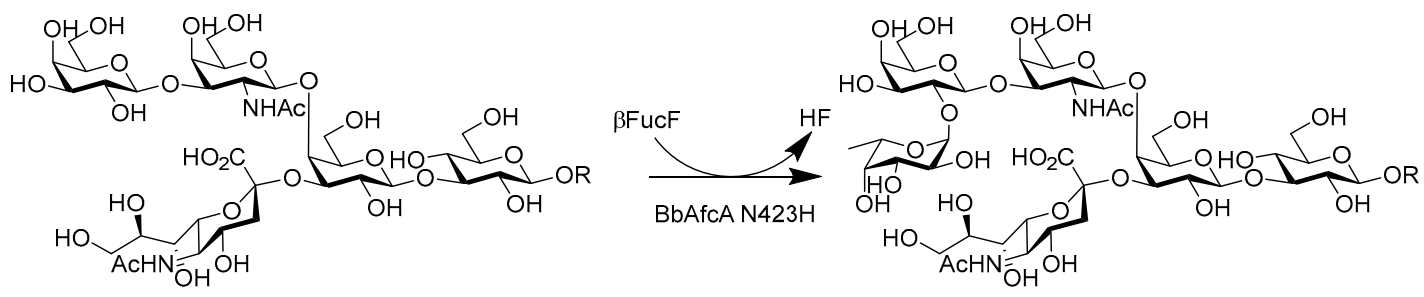

68

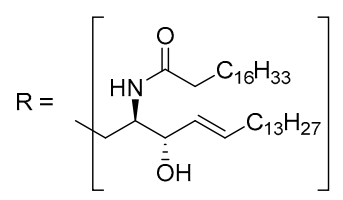

69

Scheme 12. Selective introduction of an $\alpha$-fucosyl residue to the glycoside of the GM1 ganglioside (68) demonstrated by Sugiyama et al. [61]. The enzyme BbAfcA N423H showed a broad acceptor range exhibiting fucosylation activity also towards $\mathrm{N}$ - and $\mathrm{O}$-glycans and a nonasaccharide xyloglucan.

\subsection{Glycosynthase Variants of endo- $\beta-N$-Acetylglucosaminidases}

Different from the exo- and endo-glycosidases described above, the hydrolytic mechanism of endo- $\beta-N$-acetylglucosaminidases follows a substrate-assisted pathway in which the anomeric center of the $\mathrm{N}$-acetylglucosamine located in the chitobiose moiety undergoes a nucleophilic attack by the $N$-linked acetyl group creating a oxazoline structure. This kind of activated structure can be employed by mutant forms of the endo- $\beta-N$-acetylglucosaminidases, which are deficient in the promotion of the oxazoline formation, as glycan donors in glycosynthetic reactions. The first glycosynthase like form of an endo- $\beta-N$-acetylglucosaminidase was reported by Umekawa et al. as the N175A variant of Endo-M (originating from M. hiemalis) [62]. The enzyme could utilize the oxazoline donor Man, GlcNAc-oxazoline in the synthesis of the HIV-1 gp41 glycopeptide Man, ${ }_{9} \mathrm{GlNAc}_{2} \mathrm{C} 34$, producing the glycopeptide in a yield of $72 \%$. A large improvement for the glycosynthase method 
using endo- $\beta-N$-acetylglucosaminidases was the simplified donor synthesis by Noguchi et al. $[63,64]$. The synthesis of the oxazoline structure catalyzed by 2-chloro-1,3-dimethyl-imidazolium chloride (DMC) and later 2-chloro-1,3-dimethyl-1H-benzimidazol-3-ium chloride (CDMBI) allowed the production in aqueous solution in unprotected form, therefore ideal for subsequent conversion by enzymatic glycosylation. In 2010, Umekawa et al. described a new variant Endo-M N175Q, which exhibited a much higher synthase activity and transglycosidase activity [65]. This enabled the use of natural glycan donors such as the sialoglycopeptide (SGP), though leading to a lower yield compared to the use of oxazoline donors. The variant enabled the synthesis of a high-mannose $(84 \%)$ and complex type glycoform (76\%) of the sperm antigen CD52 (70a,b) using the GlcNAc-CD52 peptide (71) as the acceptor (Scheme 13). The group also described the successful synthesis of sialo-complex-type glycoforms of the bioactive peptides PAMP12 and Substance P in yields of 95 and $98 \%$, respectively. The glycosylation reaction was also shown for the protein RNaseB bearing a single GlcNAc moiety therefore allowing glycan modification of proteins/enzymes by this method [66]. Amin et al. also described the production of monoglycoforms of RNaseB by the glycosynthase Endo-A N171A (A. protophormiae) in yields up to $80 \%$ with chemically synthesized oxazoline glycans [67].

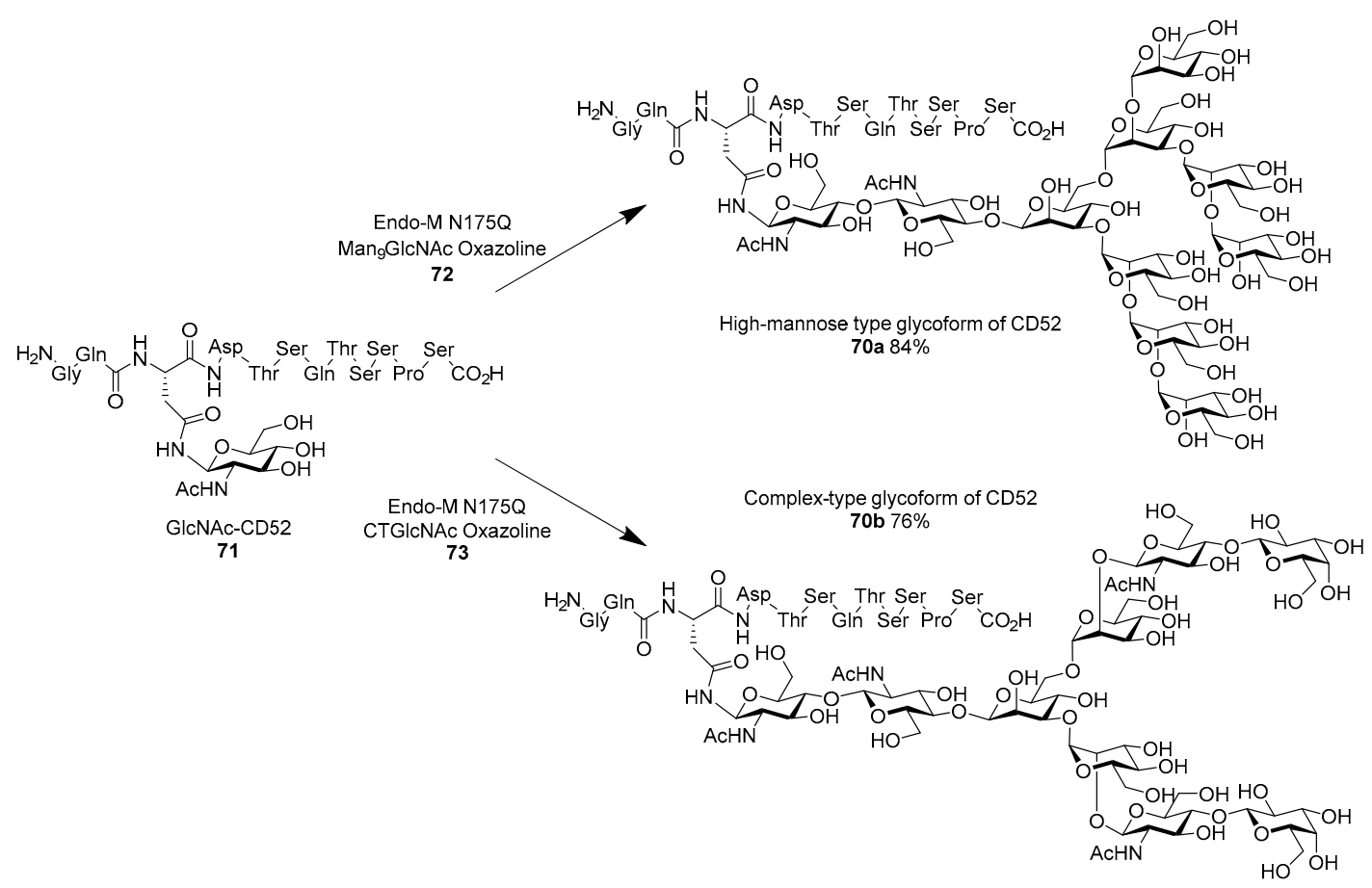

Scheme 13. Synthesis of two glycoforms of the sperm antigen CD52 $(70 \mathbf{a} / \mathbf{b})$ by the endo- $\beta-N-$ acetylglucosaminidase derived glycosynthase Endo-M N175Q [65]. The high-mannose and complex type glycoforms were produced under utilization of oxazoline donors 72, 73 and the GlcNAc-CD52 peptide (71).

The Endo-M and Endo-A glycosynthase variants were additionally employed in the synthesis of four glycoforms (yields varying from 59-96\%) of the glycopeptide pramlintide by Tomabechi et al. in an attempt to improve the low circulatory half-life and poor solubility of the pharmaceutical compound [68]. The produced glycoforms were tested in vitro and in vivo and exhibited varying properties in dependency of the type of transferred glycan and its position in the glycopeptide. The glycoform library was subsequently expanded with the same enzymes by Kowalczyk et al. to $18 \mathrm{~N}$-glycosylated pramlintide analogues bearing either a GlcNAc-, pentasaccharide-, or undecasaccharide residue at different positions of the peptide [69]. In comparison to the Endo-A and Endo-M glycosynthases, Fan et al. developed a glycosynthase variant of Endo-D originating 
from S. pneumoniae which could glycosylate fucosylated GlcNAc residues [70]. This unique property allowed the remodeling of the glycans of the IgG Fc-domain. However, the strict substrate specificity for $\mathrm{Man}_{3}$ GlcNAc oxazoline and not complex type $\mathrm{N}$-glycan oxazolines limits the use of the enzyme greatly. A more variable glycosylation of $\alpha-1,6$-fucosylated GlcNAc-polypeptides was demonstrated by Giddens et al. with the Endo-F3 mutants D165A/Q [71]. The mutant was capable of synthesizing asialo biantennary and complex triantennary core-fucosylated glycoforms of rituximab (intact antibody) in yields over $95 \%$. Further applications, indicating the high potential of the method for the synthesis of pharmaceutical relevant compounds were the chemoenzymatic production of vaccine candidates [72]; the site-selective glycosylation of HIV-1 polypeptide antigen bearing two different glycans (yields up to 95\%) [73]; the glycan remodeling of human erythropoietin (EPO) [74]; and the synthesis of mannose-6-phosphate-containing glycoproteins [75]. Tang et al. impressively demonstrated a one-pot $\mathrm{N}$-glycan remodeling of IgG proteins by combining the wild type (wt) Endo-M glycosidase with the synthase variant Endo-S D322S [76]. This synthesis comprised the donor production by Endo-M catalyzed SGP hydrolysis, subsequent conversion to the oxazoline with DMC, and donor transfer to the protein by Endo-S D322S with near complete conversion within $30 \mathrm{~min}$. Further yield improvement might be achieved by the new glycosynthase of Endo-CC (C. cinereal) recently introduced by Eshima et al. [77]. The enzyme exhibited high activity at a neutral $\mathrm{pH}$ of 7.5 in comparison to the acidic $\mathrm{pH}$ between $4-6$, which most other endo- $\beta-N$-acetylglucosaminidases require for activity. This could be a great advantage for yield improvement due to the increased stability of the oxazoline donors at this $\mathrm{pH}$ [78]. A further use of the oxazoline type donor for glycoside synthesis has been demonstrated by the production of glycosaminoglycans such as derivatives of chondroitin sulfate and hyaluronan [79-82]. However, the polymerization of the oxazolines derived from, for example $\mathrm{N}$-acetylchondrosine, was carried out with the natural forms of ovine or bovine testes hyaluronidase, therefore not utilizing the glycosynthase method and not further discussed in this review. Nevertheless, the first step to glycosynthase mediated synthesis of glycosaminoglycans such as heparan, chondroitin sulfate, and hyaluronan was demonstrated by Müllegger et al. by the synthesis of uronic acid-containing glycoconjugates catalyzed by the thermostable glycosynthase derived from T. maritima $\beta$-glucuronidase [83].

\section{Conclusions}

The enzymatic synthesis of glycosidic structures utilizing the glycosynthase approach has made many advances and is nowadays a promising alternative to classical chemical synthesis. The direct comparison of enzymatic glycosylation reactions compared to the chemical paths is difficult due to the additional protection and deprotection as well as possible modification steps needed after chemical glycosylation. When solely comparing the glycosylation reaction, the chemical pathway also in many cases produces glycosides in similar high yields (e.g., the synthesis of disaccharide $\mathbf{6 1}$ (Section 2.4, Table 2), enzymatic glycosylation 55\% yield; chemical glycosylation $61 \%$ ). However, when considering the steps required for synthesis of the acceptor and donor molecule and also the subsequent deprotection steps for the chemical pathway, the advantage of the glycosynthases becomes obvious, especially when thinking of large oligosaccharides (Table 3).

The repertoire of glycosynthase variants is successfully increasing though it is still insufficient for creating the high diversity of glycosides present throughout Nature. Great advances were acheived with the introduction of synthases derived from inverting enzymes and the recent glycosynthases derived from endo- $\beta-N$-acetylglucosaminidases that allow the production of peptides with defined glycosylation. A larger drawback, however, is still the lack of glycosynthase variants capable of glycosylating non-glycosidic structures and the formation of oligomerized side products. 
Table 3. Comparison of the required steps and yields of the chemical and enzymatic synthesis of the disaccharide Man- $\alpha(1,3)$-D- $\alpha$-pNPMan (61) [55,84-87].

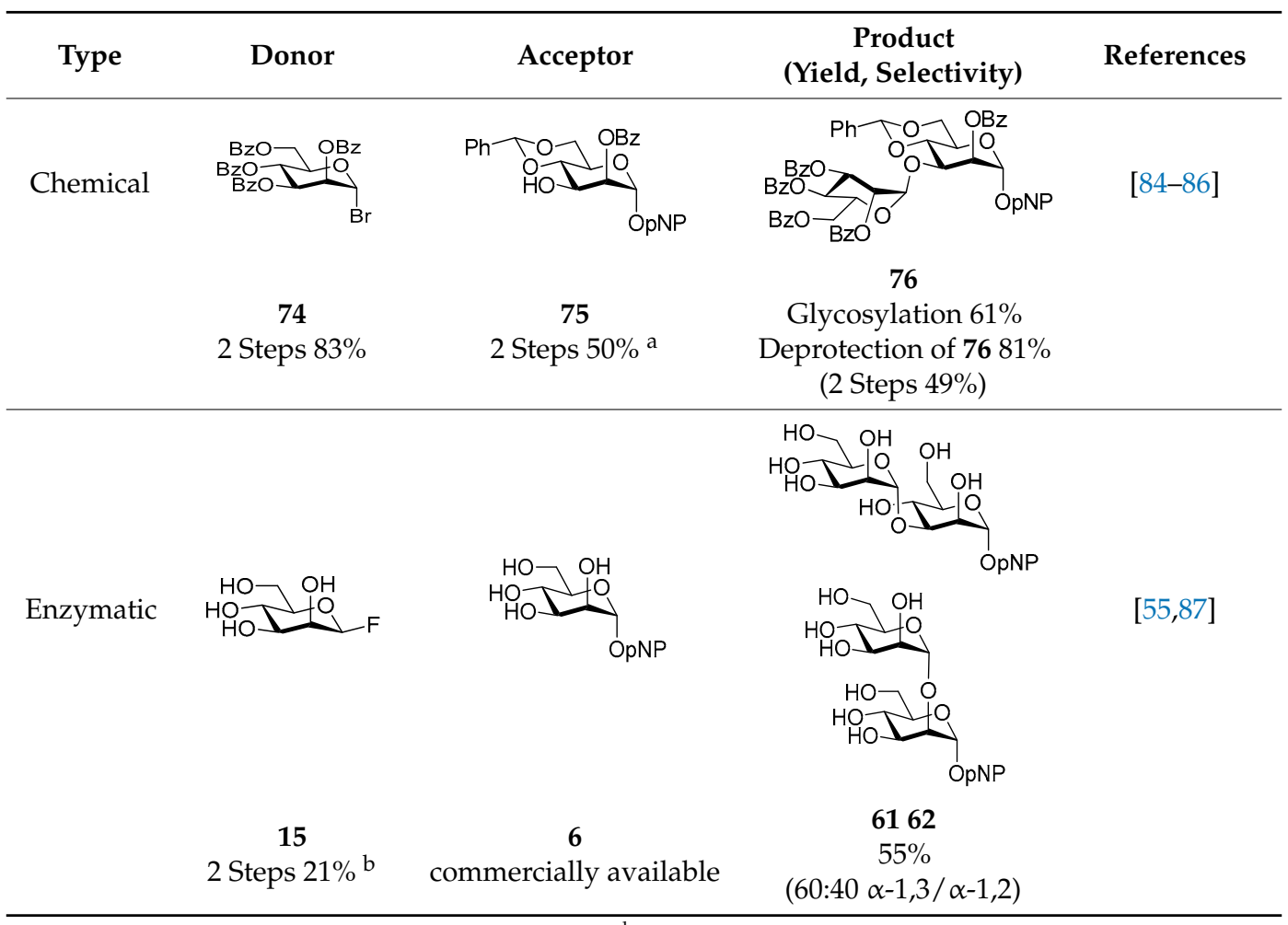

$\overline{\text { a Starting from commercially available } \alpha \text {-pNPMan (6); }{ }^{\text {b }} \text { Starting from 2,3,4,6-tetra-O-acetyl- } \beta \text {-D-mannopyranose. }}$

Further production of glycosynthase variants of glycosidases with known substrates will be vital for the progress of this method. Also progress in methods for identification and characterization of glycosynthases from mutant libraries will be critical to produce enzymes with new acceptor or donor scopes. Many advances have already been made such as biological and biochemical assays utilizing chemical complementation, fluorescence and photometric methods [50,88-90]. Subsequent analysis of structural and mechanistic details will help to identify structural requirements, which can be transferred to new glycosynthases by genetic engineering and rational design [28,91].

Acknowledgments: We gratefully acknowledge the Jürgen Manchot Stiftung for a scholarship (MH). This work was supported by the DFG within the IRTG 'SeleCa- Selectivity in Chemo- and Biocatalysis' (grant number IRTG1628).

Author Contributions: M.R.H. and J.P. wrote the paper.

Conflicts of Interest: The authors declare no conflict of interest. The founding sponsors had no role in the design of the study; in the collection, analyses, or interpretation of data; in the writing of the manuscript, and in the decision to publish the results.

\section{References}

1. Stevens, J.; Blixt, O.; Glaser, L.; Taubenberger, J.K.; Palese, P.; Paulson, J.C.; Wilson, I.A. Glycan microarray analysis of the hemagglutinins from modern and pandemic influenza viruses reveals different receptor specificities. J. Mol. Biol. 2006, 355, 1143-1155. [CrossRef] [PubMed]

2. Bode, L. Human milk oligosaccharides: Every baby needs a sugar mama. Glycobiology 2012, 22, 1147-1162. [CrossRef] [PubMed]

3. Nicolaou, K.C.; Mitchell, H.J. Adventures in carbohydrate chemistry: New synthetic technologies, chemical synthesis, molecular design, and chemical biology. Angew. Chem. Int. Ed. 2001, 40, 1576-1624. [CrossRef]

4. Douglas, N.L.; Ley, S.V.; Lucking, U.; Warriner, S.L. Tuning glycoside reactivity: New tool for efficient oligosaccharide synthesis. J. Chem. Soc. Perkin Trans. 1 1998, 51-66. [CrossRef] 
5. Grice, P.; Ley, S.V.; Pietruszka, J.; Priepke, H.W.M.; Walther, E.P.E. Tuning the reactivity of glycosides: Efficient one-pot oligosaccharide synthesis1. Synlett 1995, 1995, 781-784. [CrossRef]

6. Cheung, M.-K.; Douglas, N.L.; Hinzen, B.; Ley, S.V.; Pannecoucke, X. One-pot synthesis of tetra- and pentasaccharides from monomeric building blocks using the principles of orthogonality and reactivity tuning. Synlett 1997, 1997, 257-260. [CrossRef]

7. McArthur, J.B.; Chen, X. Glycosyltransferase engineering for carbohydrate synthesis. Biochem. Soc. Trans. 2016, 44, 129-142. [CrossRef] [PubMed]

8. Talens-Perales, D.; Polaina, J.; Marín-Navarro, J. Enzyme engineering for oligosaccharide biosynthesis. In Frontier Discoveries and Innovations in Interdisciplinary Microbiology; Shukla, P., Ed.; Springer: New Delhi, India, 2016; pp. 9-31.

9. Koshland, D.E. Stereochemistry and the mechanism of enzymatic reactions. Biol. Rev. Camb. Philos. Soc. 1953, 28, 416-436. [CrossRef]

10. Danby, P.M.; Withers, S.G. Advances in enzymatic glycoside synthesis. ACS Chem. Biol. 2016, 11, 1784-1794. [CrossRef] [PubMed]

11. Bissaro, B.; Monsan, P.; Faure, R.; O'Donohue, M.J. Glycosynthesis in a waterworld: New insight into the molecular basis of transglycosylation in retaining glycoside hydrolases. Biochem. J. 2015, 467, 17-35. [CrossRef] [PubMed]

12. Mackenzie, L.F.; Wang, Q.; Warren, R.A.J.; Withers, S.G. Glycosynthases: Mutant glycosidases for oligosaccharide synthesis. J. Am. Chem. Soc. 1998, 120, 5583-5584. [CrossRef]

13. Malet, C.; Planas, A. From $\beta$-glucanase to $\beta$-glucansynthase: Glycosyl transfer to $\alpha$-glycosyl fluorides catalyzed by a mutant endoglucanase lacking its catalytic nucleophile. FEBS Lett. 1998, 440, 208-212. [CrossRef]

14. Cobucci-Ponzano, B.; Conte, F.; Mazzone, M.; Bedini, E.; Corsaro, M.M.; Rossi, M.; Moracci, M. Design of new reaction conditions for characterization of a mutant thermophilic $\alpha$-L-fucosidase. Biocatal. Biotransform. 2008, 26, 18-24. [CrossRef]

15. Cobucci-Ponzano, B.; Zorzetti, C.; Strazzulli, A.; Bedini, E.; Corsaro, M.M.; Sulzenbacher, G.; Rossi, M.; Moracci, M. Exploitation of $\beta$-glycosyl azides for the preparation of $\alpha$-glycosynthases. Biocatal. Biotransform. 2012, 30, 288-295. [CrossRef]

16. Umekawa, M.; Huang, W.; Li, B.; Fujita, K.; Ashida, H.; Wang, L.-X.; Yamamoto, K. Mutants of mucor hiemalis endo- $\beta$ - $N$-acetylglucosaminidase show enhanced transglycosylation and glycosynthase-like activities. J. Biol. Chem. 2008, 283, 4469-4479. [CrossRef] [PubMed]

17. Bojarová, P.; Kren, V. Glycosidases in carbohydrate synthesis: When organic chemistry falls short. CHIMIA 2011, 65, 65-70. [CrossRef] [PubMed]

18. Trincone, A. Uncommon glycosidases for the enzymatic preparation of glycosides. Biomolecules 2015, 5, 2160-2183. [CrossRef] [PubMed]

19. Cobucci-Ponzano, B.; Strazzulli, A.; Rossi, M.; Moracci, M. Glycosynthases in biocatalysis. Adv. Synth. Catal. 2011, 353, 2284-2300. [CrossRef]

20. Shim, J.-H.; Chen, H.-M.; Rich, J.R.; Goddard-Borger, E.D.; Withers, S.G. Directed evolution of a $\beta$-glycosidase from Agrobacterium sp. To enhance its glycosynthase activity toward C3-modified donor sugars. Protein Eng. Des. Sel. 2012, 25, 465-472. [CrossRef] [PubMed]

21. Kim, Y.-W.; Lee, S.S.; Warren, R.A.J.; Withers, S.G. Directed evolution of a glycosynthase from Agrobacterium sp. increases its catalytic activity dramatically and expands its substrate repertoire. J. Biol. Chem. 2004, 279, 42787-42793. [CrossRef] [PubMed]

22. Wei, J.; Lv, X.; Lü, Y.; Yang, G.; Fu, L.; Yang, L.; Wang, J.; Gao, J.; Cheng, S.; Duan, Q. Glycosynthase with broad substrate specificity-An efficient biocatalyst for the construction of oligosaccharide library. Eur. J. Org. Chem. 2013, 2013, 2414-2419. [CrossRef]

23. Pengthaisong, S.; Chen, C.-F.; Withers, S.G.; Kuaprasert, B.; Ketudat Cairns, J.R. Rice BGlu1 glycosynthase and wild type transglycosylation activities distinguished by cyclophellitol inhibition. Carbohydr. Res. 2012, 352, 51-59. [CrossRef] [PubMed]

24. Fairweather, J.K.; McDonough, M.J.; Stick, R.V.; Tilbrook, D.M.G. Some approaches to glycosylated versions of methyl $\beta$-acarviosin. Aust. J. Chem. 2004, 57, 197-205. [CrossRef]

25. Macdonald, J.M.; Stick, R.V.; Tilbrook, D.M.G.; Withers, S.G. Synthesis with glycosynthases: Cello-oligomers of isofagomine and a tetrahydrooxazine as cellulase inhibitors. Aust. J. Chem. 2003, 55, 747-752. [CrossRef] 
26. Jakeman, D.L.; Sadeghi-Khomami, A. A $\beta-(1,2)$-glycosynthase and an attempted selection method for the directed evolution of glycosynthases. Biochemistry 2011, 50, 10359-10366. [CrossRef] [PubMed]

27. Pozzo, T.; Plaza, M.; Romero-García, J.; Faijes, M.; Karlsson, E.N.; Planas, A. Glycosynthases from thermotoga neapolitana $\beta$-glucosidase 1A: A comparison of $\alpha$-glucosyl fluoride and in situ-generated $\alpha$-glycosyl formate donors. J. Mol. Catal. B Enzym. 2014, 107, 132-139. [CrossRef]

28. Pozzo, T.; Romero-García, J.; Faijes, M.; Planas, A.; Nordberg Karlsson, E. Rational design of a thermostable glycoside hydrolase from family 3 introduces $\beta$-glycosynthase activity. Glycobiology 2017, 27, 165-175. [CrossRef] [PubMed]

29. Park, I.; Lee, H.; Cha, J. Glycoconjugates synthesized via transglycosylation by a thermostable $\alpha$-glucosidase from thermoplasma acidophilum and its glycosynthase mutant. Biotechnol. Lett. 2014, 36, 789-796. [CrossRef] [PubMed]

30. Yang, M.; Davies, G.J.; Davis, B.G. A glycosynthase catalyst for the synthesis of flavonoid glycosides. Angew. Chem. 2007, 119, 3959-3962. [CrossRef]

31. Codera, V.; Edgar, K.J.; Faijes, M.; Planas, A. Functionalized celluloses with regular substitution pattern by glycosynthase-catalyzed polymerization. Biomacromolecules 2016, 17, 1272-1279. [CrossRef] [PubMed]

32. Aragunde, H.; Castilla, E.; Biarnés, X.; Faijes, M.; Planas, A. A transitional hydrolase to glycosynthase mutant by glu to asp substitution at the catalytic nucleophile in a retaining glycosidase. Carbohydr. Res. 2014, 389, 85-92. [CrossRef] [PubMed]

33. Kwan, D.H.; Ernst, S.; Kötzler, M.P.; Withers, S.G. Chemoenzymatic synthesis of a type 2 blood group A tetrasaccharide and development of high-throughput assays enables a platform for screening blood group antigen-cleaving enzymes. Glycobiology 2015, 25, 806-811. [CrossRef] [PubMed]

34. Strazzulli, A.; Cobucci-Ponzano, B.; Carillo, S.; Bedini, E.; Corsaro, M.M.; Pocsfalvi, G.; Withers, S.G.; Rossi, M.; Moracci, M. Introducing transgalactosylation activity into a family $42 \beta$-galactosidase. Glycobiology 2017, 27, 425-437. [CrossRef] [PubMed]

35. Goddard-Borger, E.D.; Tysoe, C.; Withers, S.G. Glycosynthase mediated synthesis of psychosine. Carbohydr. Res. 2016, 435, 97-99. [CrossRef] [PubMed]

36. Rich, J.R.; Cunningham, A.-M.; Gilbert, M.; Withers, S.G. Glycosphingolipid synthesis employing a combination of recombinant glycosyltransferases and an endoglycoceramidase glycosynthase. Chem. Commun. 2011, 47, 10806-10808. [CrossRef] [PubMed]

37. Yang, G.-Y.; Li, C.; Fischer, M.; Cairo, C.W.; Feng, Y.; Withers, S.G. A fret probe for cell-based imaging of ganglioside-processing enzyme activity and high-throughput screening. Angew. Chem. 2015, 127, 5479-5483. [CrossRef]

38. Henze, M.; Schmidtke, S.; Hoffmann, N.; Steffens, H.; Pietruszka, J.; Elling, L. Combination of glycosyltransferases and a glycosynthase in sequential and one-pot reactions for the synthesis of type 1 and type 2 $N$-acetyllactosamine oligomers. ChemCatChem 2015, 7, 3131-3139. [CrossRef]

39. Henze, M.; You, D.-J.; Kamerke, C.; Hoffmann, N.; Angkawidjaja, C.; Ernst, S.; Pietruszka, J.; Kanaya, S.; Elling, L. Rational design of a glycosynthase by the crystal structure of $\beta$-galactosidase from Bacillus circulans $(\mathrm{BgaC})$ and its use for the synthesis of $\mathrm{N}$-acetyllactosamine type 1 glycan structures. J. Biotechnol. 2014, 191, 78-85. [CrossRef] [PubMed]

40. Cobucci-Ponzano, B.; Zorzetti, C.; Strazzulli, A.; Carillo, S.; Bedini, E.; Corsaro, M.M.; Comfort, D.A.; Kelly, R.M.; Rossi, M.; Moracci, M. A novel $\alpha$-D-galactosynthase from thermotoga maritima converts $\beta$-D-galactopyranosyl azide to $\alpha$-galacto-oligosaccharides. Glycobiology 2011, 21, 448-456. [CrossRef] [PubMed]

41. Okuyama, M.; Matsunaga, K.; Watanabe, K.-I.; Yamashita, K.; Tagami, T.; Kikuchi, A.; Ma, M.; Klahan, P.; Mori, H.; Yao, M. Efficient synthesis of $\alpha$-galactosyl oligosaccharides using a mutant bacteroides thetaiotaomicron retaining $\alpha$-galactosidase (BtGh97b). FEBS J. 2017, 284, 766-783. [CrossRef] [PubMed]

42. Bayon, C.; Moracci, M.; Hernaiz, M.J. A novel, efficient and sustainable strategy for the synthesis of $\alpha$-glycoconjugates by combination of a $\alpha$-galactosynthase and a green solvent. RSC Adv. 2015, 5, 55313-55320. [CrossRef]

43. Vázquez, M.J.; Alonso, J.L.; Domínguez, H.; Parajó, J.C. Xylooligosaccharides: Manufacture and applications. Trends Food Sci. Technol. 2000, 11, 387-393. [CrossRef]

44. Kim, Y.-W.; Chen, H.; Withers, S.G. Enzymatic transglycosylation of xylose using a glycosynthase. Carbohydr. Res. 2005, 340, 2735-2741. [CrossRef] [PubMed] 
45. Honda, Y.; Kitaoka, M. The first glycosynthase derived from an inverting glycoside hydrolase. J. Biol. Chem. 2006, 281, 1426-1431. [CrossRef] [PubMed]

46. Kim, Y.-W.; Fox, D.T.; Hekmat, O.; Kantner, T.; McIntosh, L.P.; Warren, R.A.J.; Withers, S.G. Glycosynthase-based synthesis of xylo-oligosaccharides using an engineered retaining xylanase from cellulomonas fimi. Org. Biomol. Chem. 2006, 4, 2025-2032. [CrossRef] [PubMed]

47. Sugimura, M.; Nishimoto, M.; Kitaoka, M. Characterization of glycosynthase mutants derived from glycoside hydrolase family 10 xylanases. Biosci. Biotechnol. Biochem. 2006, 70, 1210-1217. [CrossRef] [PubMed]

48. Ben-David, A.; Bravman, T.; Balazs, Y.S.; Czjzek, M.; Schomburg, D.; Shoham, G.; Shoham, Y. Glycosynthase activity of geobacillus stearothermophilus GH52 $\beta$-xylosidase: Efficient synthesis of xylooligosaccharides from $\alpha$-D-xylopyranosyl fluoride through a conjugated reaction. ChemBioChem 2007, 8, 2145-2151. [CrossRef] [PubMed]

49. Khasin, A.; Alchanati, I.; Shoham, Y. Purification and characterization of a thermostable xylanase from bacillus stearothermophilus T-6. Appl. Environ. Microbiol. 1993, 59, 1725-1730. [PubMed]

50. Ben-David, A.; Shoham, G.; Shoham, Y. A universal screening assay for glycosynthases: Directed evolution of glycosynthase XynB2(E335G) suggests a general path to enhance activity. Chem. Biol. 2008, 15, 546-551. [CrossRef] [PubMed]

51. Goddard-Borger, E.D.; Fiege, B.; Kwan, E.M.; Withers, S.G. Glycosynthase-mediated assembly of xylanase substrates and inhibitors. ChemBioChem 2011, 12, 1703-1711. [CrossRef] [PubMed]

52. Trincone, A.; Cobucci-Ponzano, B.; Di Lauro, B.; Rossi, M.; Mitsuishi, Y.; Moracci, M. Enzymatic synthesis and hydrolysis of xylogluco-oligosaccharides using the first archaeal $\alpha$-xylosidase from sulfolobus solfataricus. Extremophiles 2001, 5, 277-282. [CrossRef] [PubMed]

53. Spadiut, O.; Ibatullin, F.M.; Peart, J.; Gullfot, F.; Martinez-Fleites, C.; Ruda, M.; Xu, C.; Sundqvist, G.; Davies, G.J.; Brumer, H. Building custom polysaccharides in vitro with an efficient, broad-specificity xyloglucan glycosynthase and a fucosyltransferase. J. Am. Chem. Soc. 2011, 133, 10892-10900. [CrossRef] [PubMed]

54. Nashiru, O.; Zechel, D.L.; Stoll, D.; Mohammadzadeh, T.; Warren, R.A.J.; Withers, S.G. $\beta$-mannosynthase: Synthesis of $\beta$-mannosides with a mutant $\beta$-mannosidase. Angew. Chem. 2001, 113, 431-434. [CrossRef]

55. Yamamoto, K.; Davis, B.G. Creation of an $\alpha$-mannosynthase from a broad glycosidase scaffold. Angew. Chem. 2012, 124, 7567-7571. [CrossRef]

56. Jahn, M.; Stoll, D.; Warren, R.A.J.; Szabo, L.; Singh, P.; Gilbert, H.J.; Ducros, V.M.A.; Davies, G.J.; Withers, S.G. Expansion of the glycosynthase repertoire to produce defined manno-oligosaccharides. Chem. Commun. 2003, 12, 1327-1329. [CrossRef]

57. Wada, J.; Honda, Y.; Nagae, M.; Kato, R.; Wakatsuki, S.; Katayama, T.; Taniguchi, H.; Kumagai, H.; Kitaoka, M.; Yamamoto, K. 1,2- $\alpha$-L-fucosynthase: A glycosynthase derived from an inverting $\alpha$-glycosidase with an unusual reaction mechanism. FEBS Lett. 2008, 582, 3739-3743. [CrossRef] [PubMed]

58. Cobucci-Ponzano, B.; Conte, F.; Bedini, E.; Corsaro, M.M.; Parrilli, M.; Sulzenbacher, G.; Lipski, A.; Dal Piaz, F.; Lepore, L.; Rossi, M. $\beta$-glycosyl azides as substrates for $\alpha$-glycosynthases: Preparation of efficient $\alpha$-L-fucosynthases. Chem. Biol. 2009, 16, 1097-1108. [CrossRef] [PubMed]

59. Sakurama, H.; Fushinobu, S.; Hidaka, M.; Yoshida, E.; Honda, Y.; Ashida, H.; Kitaoka, M.; Kumagai, H.; Yamamoto, K.; Katayama, T. 1,3-1,4- $\alpha$-L-fucosynthase that specifically introduces lewis a/x antigens into type-1/2 chains. J. Biol. Chem. 2012, 287, 16709-16719. [CrossRef] [PubMed]

60. Sugiyama, Y.; Gotoh, A.; Katoh, T.; Honda, Y.; Yoshida, E.; Kurihara, S.; Ashida, H.; Kumagai, H.; Yamamoto, K.; Kitaoka, M. Introduction of $\mathrm{H}$-antigens into oligosaccharides and sugar chains of glycoproteins using highly efficient 1,2- $\alpha$-L-fucosynthase. Glycobiology 2016, 26, 1235-1247. [CrossRef] [PubMed]

61. Sugiyama, Y.; Katoh, T.; Honda, Y.; Gotoh, A.; Ashida, H.; Kurihara, S.; Yamamoto, K.; Katayama, T. Application study of 1,2- $\alpha$-L-fucosynthase: Introduction of Fuc $\alpha 1-2 \mathrm{Gal}$ disaccharide structures on N-glycan, ganglioside, and xyloglucan oligosaccharide. Biosci. Biotechnol. Biochem. 2017, 81, 283-291. [CrossRef] [PubMed]

62. Huang, W.; Ochiai, H.; Zhang, X.; Wang, L.-X. Introducing N-glycans into natural products through a chemoenzymatic approach. Carbohydr. Res. 2008, 343, 2903-2913. [CrossRef] [PubMed] 
63. Noguchi, M.; Tanaka, T.; Gyakushi, H.; Kobayashi, A.; Shoda, S.-I. Efficient synthesis of sugar oxazolines from unprotected $\mathrm{N}$-acetyl-2-amino sugars by using chloroformamidinium reagent in water. J. Org. Chem. 2009, 74, 2210-2212. [CrossRef] [PubMed]

64. Noguchi, M.; Fujieda, T.; Huang, W.C.; Ishihara, M.; Kobayashi, A.; Shoda, S.-I. A practical one-step synthesis of 1,2-oxazoline derivatives from unprotected sugars and its application to chemoenzymatic $\beta$ $\mathrm{N}$-acetylglucosaminidation of disialo-oligosaccharide. Helv. Chim. Acta 2012, 95, 1928-1936. [CrossRef]

65. Umekawa, M.; Li, C.; Higashiyama, T.; Huang, W.; Ashida, H.; Yamamoto, K.; Wang, L.-X. Efficient glycosynthase mutant derived from mucor hiemalis endo- $\beta-N$-acetylglucosaminidase capable of transferring oligosaccharide from both sugar oxazoline and natural N-glycan. J. Biol. Chem. 2010, 285, 511-521. [CrossRef] [PubMed]

66. Sakaguchi, K.; Katoh, T.; Yamamoto, K. Transglycosidase-like activity of mucor hiemalis endoglycosidase mutants enabling the synthesis of glycoconjugates using a natural glycan donor. Biotechnol. Appl. Biochem. 2016, 63, 812-819. [CrossRef] [PubMed]

67. Amin, M.N.; Huang, W.; Mizanur, R.M.; Wang, L.-X. Convergent synthesis of homogeneous glc1man9glcnac2-protein and derivatives as ligands of molecular chaperones in protein quality control. J. Am. Chem. Soc. 2011, 133, 14404-14417. [CrossRef] [PubMed]

68. Tomabechi, Y.; Krippner, G.; Rendle, P.M.; Squire, M.A.; Fairbanks, A.J. Glycosylation of pramlintide: Synthetic glycopeptides that display in vitro and in vivo activities as amylin receptor agonists. Chem. Eur. J. 2013, 19, 15084-15088. [CrossRef] [PubMed]

69. Kowalczyk, R.; Brimble, M.A.; Tomabechi, Y.; Fairbanks, A.J.; Fletcher, M.; Hay, D.L. Convergent chemoenzymatic synthesis of a library of glycosylated analogues of pramlintide: Structure-activity relationships for amylin receptor agonism. Org. Biomol. Chem. 2014, 12, 8142-8151. [CrossRef] [PubMed]

70. Fan, S.-Q.; Huang, W.; Wang, L.-X. Remarkable transglycosylation activity of glycosynthase mutants of endo-d, an endo- $\beta-N$-acetylglucosaminidase from streptococcus pneumoniae. J. Biol. Chem. 2012, 287, 11272-11281. [CrossRef] [PubMed]

71. Giddens, J.P.; Lomino, J.V.; Amin, M.N.; Wang, L.-X. Endo-f3 glycosynthase mutants enable chemoenzymatic synthesis of core-fucosylated triantennary complex type glycopeptides and glycoproteins. J. Biol. Chem. 2016, 291, 9356-9370. [CrossRef] [PubMed]

72. McIntosh, J.D.; Brimble, M.A.; Brooks, A.E.S.; Dunbar, P.R.; Kowalczyk, R.; Tomabechi, Y.; Fairbanks, A.J. Convergent chemo-enzymatic synthesis of mannosylated glycopeptides; targeting of putative vaccine candidates to antigen presenting cells. Chem. Sci. 2015, 6, 4636-4642. [CrossRef] [PubMed]

73. Toonstra, C.; Amin, M.N.; Wang, L.-X. Site-selective chemoenzymatic glycosylation of an HIV-1 polypeptide antigen with two distinct $N$-glycans via an orthogonal protecting group strategy. J. Org. Chem. 2016, 81, 6176-6185. [CrossRef] [PubMed]

74. Yang, Q.; An, Y.; Zhu, S.; Zhang, R.; Loke, C.M.; Cipollo, J.F.; Wang, L.-X. Glycan remodeling of human erythropoietin (EPO) through combined mammalian cell engineering and chemoenzymatic transglycosylation. ACS Chem. Biol. 2017, 12, 1665-1673. [CrossRef] [PubMed]

75. Yamaguchi, T.; Amin, M.N.; Toonstra, C.; Wang, L.-X. Chemoenzymatic synthesis and receptor binding of mannose-6-phosphate (M6P)-containing glycoprotein ligands reveal unusual structural requirements for M6P receptor recognition. J. Am. Chem. Soc. 2016, 138, 12472-12485. [CrossRef] [PubMed]

76. Tang, F.; Yang, Y.; Tang, Y.; Tang, S.; Yang, L.; Sun, B.; Jiang, B.; Dong, J.; Liu, H.; Huang, M.; et al. One-pot $\mathrm{N}$-glycosylation remodeling of igg with non-natural sialylglycopeptides enables glycosite-specific and dual-payload antibody-drug conjugates. Org. Biomol. Chem. 2016, 14, 9501-9518. [CrossRef] [PubMed]

77. Eshima, Y.; Higuchi, Y.; Kinoshita, T.; Nakakita, S.-I.; Takegawa, K. Transglycosylation activity of glycosynthase mutants of endo- $\beta-N$-acetylglucosaminidase from coprinopsis cinerea. PLoS ONE 2015, 10, e0132859. [CrossRef] [PubMed]

78. Higuchi, Y.; Eshima, Y.; Huang, Y.; Kinoshita, T.; Sumiyoshi, W.; Nakakita, S.-I.; Takegawa, K. Highly efficient transglycosylation of sialo-complex-type oligosaccharide using coprinopsis cinerea endoglycosidase and sugar oxazoline. Biotechnol. Lett. 2017, 39, 157-162. [CrossRef] [PubMed]

79. Kobayashi, S.; Morii, H.; Itoh, R.; Kimura, S.; Ohmae, M. Enzymatic polymerization to artificial hyaluronan: A novel method to synthesize a glycosaminoglycan using a transition state analogue monomer. J. Am. Chem. Soc. 2001, 123, 11825-11826. [CrossRef] [PubMed] 
80. Fujikawa, S.-I.; Ohmae, M.; Kobayashi, S. Enzymatic synthesis of chondroitin 4-sulfate with well-defined structure. Biomacromolecules 2005, 6, 2935-2942. [CrossRef] [PubMed]

81. Ochiai, H.; Ohmae, M.; Mori, T.; Kobayashi, S. Bottom-up synthesis of hyaluronan and its derivatives via enzymatic polymerization: Direct incorporation of an amido functional group. Biomacromolecules 2005, 6, 1068-1084. [CrossRef] [PubMed]

82. Kobayashi, S.; Ohmae, M.; Ochiai, H.; Fujikawa, S.-I. A hyaluronidase supercatalyst for the enzymatic polymerization to synthesize glycosaminoglycans. Chem. Eur. J. 2006, 12, 5962-5971. [CrossRef] [PubMed]

83. Müllegger, J.; Chen, H.-M.; Chan, W.Y.; Reid, S.P.; Jahn, M.; Warren, R.A.J.; Salleh, H.M.; Withers, S.G. Thermostable glycosynthases and thioglycoligases derived from thermotoga maritima $\beta$-glucuronidase. ChemBioChem 2006, 7, 1028-1030. [CrossRef] [PubMed]

84. Mach, M.; Schlueter, U.; Mathew, F.; Fraser-Reid, B.; Hazen, K.C. Comparing n-pentenyl orthoesters and n-pentenyl glycosides as alternative glycosyl donors. Tetrahedron 2002, 58, 7345-7354. [CrossRef]

85. Lerchen, H.-G.; von dem Bruch, K.; Peterson, U.; Baumgarten, J.; Piel, N.; Antonicek, H.-P.; Weichel, W.; Sperzel, M.; Bremm, K.D. Sugar-Modified Cytostatics. U.S. Patent US6271342 B1, 7 August 2001.

86. Ekborg, G.; Glaudemans, C.P.J. p-Nitrophenyl 2-, and 3-O- $\alpha$-D-mannopyranosyl- $\alpha$-D-mannopyranoside. Carbohydr. Res. 1984, 134, 83-87. [CrossRef]

87. Albert, M.; Repetschnigg, W.; Ortner, J.; Gomes, J.; Paul, B.J.; Illaszewicz, C.; Weber, H.; Steiner, W.; Dax, K. Simultaneous detection of different glycosidase activities by ${ }^{19}$ F-NMR spectroscopy. Carbohydr. Res. 2000, 326, 395-400. [CrossRef]

88. Andrés, E.; Aragunde, H.; Planas, A. Screening glycosynthase libraries with a fluoride chemosensor assay independently of enzyme specificity: Identification of a transitional hydrolase to synthase mutant. Biochem. J. 2014, 458, 355-363. [CrossRef] [PubMed]

89. Hayes, M.R.; Bochinsky, K.A.; Seibt, L.S.; Elling, L.; Pietruszka, J. Development of a colourimetric assay for glycosynthases. J. Biotechnol. 2017, 257, 162-170. [CrossRef] [PubMed]

90. Tao, H.; Peralta-Yahya, P.; Decatur, J.; Cornish, V.W. Characterization of a new glycosynthase cloned by using chemical complementation. ChemBioChem 2008, 9, 681-684. [CrossRef] [PubMed]

91. Honda, Y.; Arai, S.; Suzuki, K.; Kitaoka, M.; Fushinobu, S. The crystal structure of an inverting glycoside hydrolase family 9 exo- $\beta$-D-glucosaminidase and the design of glycosynthase. Biochem. J. 2016, 473, 463-472. [CrossRef] [PubMed] 